\title{
Article
}

\section{Pressure-Induced Magnetic Switching and Linkage Isomerism in KFe[Cr(CN)]-16HO: X-ray Absorption and Magnetic Circular Dichroism Studies}

Eugenio Coronado, M. Carmen Gime\#nez-Lo\#pez, Tomasz Korzeniak, Georgiy Levchenko, Francisco M. Romero, Alfredo Segura, Valenti\#n Garci\#a-Baonza, Julio C. Cezar, Frank M. F. de Groot, Alla Milner, and Moshe Paz-Pasternak

J. Am. Chem. Soc., 2008, 130 (46), 15519-15532 • DOI: 10.1021/ja8047046 • Publication Date (Web): 21 October 2008

Downloaded from http://pubs.acs.org on January 15, 2009
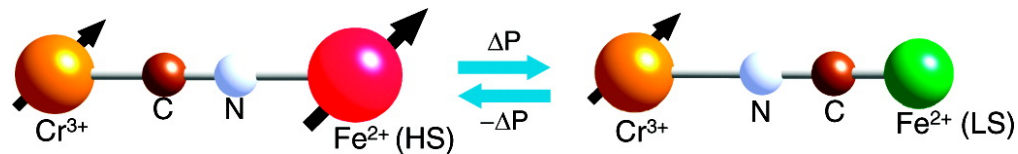

\section{More About This Article}

Additional resources and features associated with this article are available within the HTML version:

- $\quad$ Supporting Information

- Access to high resolution figures

- $\quad$ Links to articles and content related to this article

- Copyright permission to reproduce figures and/or text from this article

View the Full Text HTML 


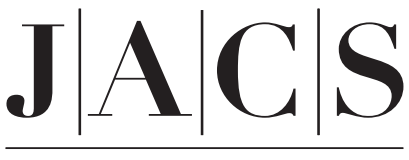

A R T I C L E S

Published on Web 10/21/2008

\title{
Pressure-Induced Magnetic Switching and Linkage Isomerism in $\mathrm{K}_{0.4} \mathrm{Fe}_{4}\left[\mathrm{Cr}(\mathrm{CN})_{6}\right]_{2.8} \cdot 16 \mathrm{H}_{2} \mathrm{O}: \mathrm{X}$-ray Absorption and Magnetic Circular Dichroism Studies
}

\author{
Eugenio Coronado, ${ }^{, \dagger}$ M. Carmen Giménez-López, ${ }^{\dagger}$ Tomasz Korzeniak, ${ }^{\dagger, \nabla}$ \\ Georgiy Levchenko, ${ }^{\dagger}$ Francisco M. Romero, ${ }^{*,}{ }^{\dagger}$ Alfredo Segura, ${ }^{\ddagger}$ \\ Valentín García-Baonza, ${ }^{\S}$ Julio C. Cezar," Frank M. F. de Groot, ${ }^{\perp}$ Alla Milner," and \\ Moshe Paz-Pasternak ${ }^{\#}$ \\ Instituto de Ciencia Molecular, Universitat de València, Polígon La Coma s/n, 46980 Paterna, \\ Spain, ICMUV, Departamento de Física Aplicada, Universitat de València, Edificio de \\ Investigación, Dr. Moliner, 50, 46100 Burjassot, Spain, Departamento de Química Física I, \\ Facultad de Ciencias Químicas, Universidad Complutense de Madrid, 28040 Madrid, Spain, \\ European Synchrotron Radiation Facility, Boîte Postale 220, 38043 Grenoble Cédex, France, \\ Department of Inorganic Chemistry and Catalysis, Utrecht University, Sorbonnelaan 16, \\ 3584 Utrecht, The Netherlands, School of Physics and Astronomy, Tel Aviv University, \\ 69978 Tel Aviv, Israel, and Faculty of Chemistry, Jagiellonian University, Kraków, Poland
}

Received June 19, 2008; E-mail: fmrm@uv.es

\begin{abstract}
The effect of applied pressure on the magnetic properties of the Prussian blue analogue $\mathrm{K}_{0.4} \mathrm{Fe}_{4}\left[\mathrm{Cr}(\mathrm{CN})_{6}\right]_{2.8} \cdot 16 \mathrm{H}_{2} \mathrm{O}$ (1) has been analyzed by dc and ac magnetic susceptibility measurements. Under ambient conditions, 1 orders ferromagnetically at a critical temperature $\left(T_{\mathrm{C}}\right)$ of $18.5 \mathrm{~K}$. Under application of pressure in the $0-1200 \mathrm{MPa}$ range, the magnetization of the material decreases and its critical temperature shifts to lower temperatures, reaching $T_{\mathrm{C}}=7.5 \mathrm{~K}$ at $1200 \mathrm{MPa}$. Pressure-dependent Raman and Mössbauer spectroscopy measurements show that this striking behavior is due to the isomerization of some $\mathrm{Cr}^{\prime \prime \prime}-\mathrm{C} \equiv \mathrm{N}-\mathrm{Fe}^{\prime \prime}$ linkages to the $\mathrm{Cr} \mathrm{r}^{\mathrm{III}}-\mathrm{N} \equiv \mathrm{C}-\mathrm{Fe}^{\mathrm{II}}$ form. As a result, the ligand field around the iron(II) centers increases, and the diamagnetic low-spin state is populated. As the number of diamagnetic centers in the cubic lattice increases, the net magnetization and critical temperature of the material decrease considerably. The phenomenon is reversible: releasing the pressure restores the magnetic properties of the original material. However, we have found that under more severe pressure conditions, a metastable sample containing $22 \% \mathrm{Cr}^{\prime \prime \prime}-\mathrm{N} \equiv \mathrm{C}-\mathrm{Fe}^{\prime \prime}$ linkages can be obtained. X-ray absorption spectroscopy and magnetic circular dichroism of this metastable sample confirm the linkage isomerization process.
\end{abstract}

\section{Introduction}

The old family of bimetallic cyanide complexes (also referred to as Prussian blue analogues) having the general formula $\mathrm{C}_{c} \mathrm{~A}_{a}\left[\mathrm{~B}(\mathrm{CN})_{6}\right]_{b} \cdot n \mathrm{H}_{2} \mathrm{O}(\mathrm{C}=$ alkali cation; $\mathrm{A}, \mathrm{B}=$ transitionmetal ions) is nowadays affording a collection of moleculebased materials with very interesting properties related to applications such as electrochromism, ion exchange, ion detection, hydrogen storage, biosensing, electro- and photocatalysis, batteries, etc. ${ }^{1-5}$ The basis of most of these practical aspects is

†nstituto de Ciencia Molecular, Universitat de València.

\$Departamento de Física Aplicada, Universitat de València.

${ }^{\S}$ Universidad Complutense de Madrid.

"European Synchrotron Radiation Facility.

${ }^{\perp}$ Utrecht University.

\# Tel Aviv University.

$\nabla$ Jagiellonian University.

(1) Itaya, K.; Uchida, I.; Neff, V. D. Acc. Chem. Res. 1986, 19, 162-168.

(2) de Tacconi, N. R.; Rajeshwar, K.; Lezna, R. O. Chem. Mater. 2003, 15, 3046-3062.

(3) Ricci, F.; Palleschi, G. Biosens. Bioelectron. 2005, 21, 389-407.

(4) Mortimer, R. J. Chem. Soc. Rev. 1997, 26, 147-156.

(5) Kaye, S. S.; Long, J. R. Chem. Commun. 2007, 4486-4488. electronic delocalization between the metal sites across the bridging cyanide anion. Indeed, Prussian blue analogues are mixed-valence compounds that can exhibit relatively high electrical conductivity via transport of both ions and electrons. In this sense, they closely resemble some transition-metal oxides and sulfides known as intercalation compounds.

At the same time, increasing attention has been devoted to the magnetism of these materials. Even if electron delocalization is crucial for the understanding of their electronic and optical properties, the magnetic behavior of these compounds can be explained using a localized orbital approach. ${ }^{6}$ This simple and elegant picture of the magnetic interactions in bimetallic cyanides has yielded a solid strategy for the design of moleculebased magnets with high Curie temperatures $\left(T_{\mathrm{C}}\right) \cdot{ }^{7-9}$ Magnetic ordering above room temperature has been achieved in some cases. $^{10,11}$

A second generation of magnetic materials based on Prussian blue analogues takes advantage of the combination of electroactivity and charge-transfer properties with the strong magnetic

(6) Verdaguer, M. Polyhedron 2001, 20, 1115-1128. 
interactions mediated by the cyanide anion. Two types of systems can be considered in this respect: (1) magnetic thin films ${ }^{12-15}$ showing high $T_{\mathrm{C}}$ values and interesting magnetooptical effects ${ }^{16}$ and (2) magnets that can be very sensitive to an external perturbation. ${ }^{17}$ Research in this area has been propelled by the pioneering work on the photoinduced magnetization of a cobalt-iron cyanide. ${ }^{18-23}$ Reversible switching of the magnetization or magnetic-pole inversion ${ }^{24}$ mediated by various physical and chemical stimuli (visible light, ${ }^{25,26} \mathrm{X}$ rays ${ }^{27}$ pressure ${ }^{28}$ temperature, ${ }^{29}$ electrochemical potential, ${ }^{12}$ or degree of solvation ${ }^{30,31}$ ) has been observed, and the key role played by electron transfer in all of these processes has been clearly established.

Besides electron transfer, this class of compounds can undergo other internal chemical processes involving drastic changes in their structures, the most important of these being linkage isomerization. ${ }^{32}$ The influence of external variables (light, pressure, or temperature) on linkage isomerization processes is well-known in coordination chemistry, ${ }^{33,34}$ and several examples

(7) Gadet, V.; Mallah, T.; Castro, I.; Verdaguer, M.; Veillet, P. J. Am. Chem. Soc. 1992, 114, 9213-9214.

(8) Mallah, T.; Thiébaut, S.; Verdaguer, M.; Veillet, P. Science 1993, 262, $1554-1557$.

(9) Entley, W. R.; Girolami, G. S. Science 1995, 268, 397-400.

(10) Ferlay, S.; Mallah, T.; Ouahès, R.; Veillet, P.; Verdaguer, M. Nature 1995, 378, 701-703.

(11) Garde, R.; Villain, F.; Verdaguer, M. J. Am. Chem. Soc. 2002, 124, 10531-10538.

(12) Sato, O.; Iyoda, T.; Fujishima, A.; Hashimoto, K. Science 1996, 271, $49-51$.

(13) Ohkoshi, S.; Fujishima, A.; Hashimoto, K. J. Am. Chem. Soc. 1998, 120, 5349-5350.

(14) Mizuno, M.; Ohkoshi, S.; Hashimoto, K. Adv. Mater. 2000, 12, 1955 1958.

(15) Buschmann, W. E.; Paulson, S. C.; Wynn, C. M.; Girtu, M. A.; Epstein, A. J.; White, H. S.; Miller, J. S. Chem. Mater. 1998, 10, 1386-1395.

(16) Ohkoshi, S.; Mizuno, M.; Hung, G.; Hashimoto, K. J. Phys. Chem. B 2000, 104, 9365-9367.

(17) Sato, O.; Tao, J.; Zhang, Y. Z. Angew. Chem., Int. Ed. 2007, 46, 2152 2187.

(18) Sato, O.; Iyoda, T.; Fujishima, A.; Hashimoto, K. Science 1996, 272, 704-705.

(19) Sato, O.; Einaga, Y.; Fujishima, A.; Hashimoto, K. Inorg. Chem. 1999, $38,4405-4412$

(20) Shimamoto, N.; Ohkoshi, S.; Sato, O.; Hashimoto, K. Inorg. Chem 2002, 41, 678-684.

(21) Bleuzen, A.; Lomenech, C.; Escax, V.; Villain, F.; Varret, F.; Cartier dit Moulin, C.; Verdaguer, M. J. Am. Chem. Soc. 2000, 122, 66486652.

(22) Cartier dit Moulin, C.; Villain, F.; Bleuzen, A.; Arrio, M. A.; Sainctavit, P.; Lomenech, C.; Escax, V.; Baudelet, F.; Dartyge, E.; Gallet, J. J.; Verdaguer, M. J. Am. Chem. Soc. 2000, 122, 6653-6658.

(23) Escax, V.; Bleuzen, A.; Cartier dit Moulin, C.; Villain, F.; Goujon, A.; Varret, F.; Verdaguer, M. J. Am. Chem. Soc. 2001, 123, 1253612546.

(24) Ohkoshi, S.; Hashimoto, K. J. Am. Chem. Soc. 1999, 121, 1059110597.

(25) Goujon, A.; Roubeau, O.; Varret, F.; Dolbecq, A.; Bleuzen, A.; Verdaguer, M. Eur. Phvs. J. B 2000, 14, 115-124.

(26) Tokoro, H.; Matsuda, M.; Hashimoto, K.; Ohkoshi, S. J. Appl. Phvs. 2005, 97, 508-510.

(27) Margadonna, S.; Prassides, K.; Fitch, A. N. Angew. Chem., Int. Ed. 2004, 43, 6316-6319.

(28) Ksenofontov, V.; Levchenko, G.; Reiman, S.; Gütlich, P.; Bleuzen, A.; Escax, V.; Verdaguer, M. Phys. Rev. B 2003, 68, 024415.

(29) Ohkoshi, S.; Tokoro, H.; Hashimoto, K. Coord. Chem. Rev. 2005, $249,1830-1840$.

(30) Sato, Y.; Ohkoshi, S.; Arai, K.; Tozawa, M.; Hashimoto, K. J. Am. Chem. Soc. 2003, 125, 14590-14595.

(31) Ohkoshi, S.; Arai, K.; Sato, Y.; Hashimoto, K. Nat. Mater. 2004, 3 , 857-861.

(32) Buschmann, W. E.; Ensling, J.; Gütlich, P.; Miller, J. S. Chem.-Eur. I. 1999, 5, 3019-3028.

(33) Kishi, S.; Kato, M. Inorg. Chem. 2003, 42, 8728-8734. of bistability have been reported. ${ }^{35,36}$ Surprisingly, despite the fact that isomerization of the cyanide-metal bond should have an obvious impact on the transition-metal electronic states, the possibility of tuning the magnetization of Prussian blue analogues via this structural rearrangement has not yet been explored. We have focused our attention on the thermally induced irreversible transformation of the "red isomer" iron(II) hexacyanochromate(III), $\mathrm{Fe}_{3}\left[\mathrm{Cr}(\mathrm{CN})_{6}\right]_{2}$, to the "green isomer" chromium(III) hexacyanoferrate(II), $\mathrm{Cr}_{4}\left[\mathrm{Fe}(\mathrm{CN})_{6}\right]_{3}$, which was reported almost 40 years ago. ${ }^{37-39}$ In this reaction, the $\mathrm{Fe}^{2+}$ cations exhibit a modification of their ground spin state from an initial high-spin (HS) configuration where Fe is bonded to $\mathrm{N}$ to a final low-spin (LS) configuration where $\mathrm{Fe}$ is bonded to C. The process takes place with an important contraction of the structure ( $\sim 15 \%$ by volume), suggesting the possibility of driving the transformation in a controlled way by applying pressure. In a previous communication, we reported on the importance of linkage isomerism in the reversible pressureinduced switching of the magnetization of the molecular magnet $\mathrm{K}_{0.4} \mathrm{Fe}_{4}\left[\mathrm{Cr}(\mathrm{CN})_{6}\right]_{2.8} \cdot 16 \mathrm{H}_{2} \mathrm{O}(\mathbf{1}){ }^{40}$ It was demonstrated that under a mechanical perturbation, some of the $\mathrm{Cr}^{\mathrm{III}}-\mathrm{C} \equiv \mathrm{N}-\mathrm{Fe}^{\mathrm{II}}$ linkages present in the compound isomerize to the $\mathrm{Cr}^{\mathrm{III}}-$ $\mathrm{N} \equiv \mathrm{C}-\mathrm{Fe}^{\mathrm{II}}$ form. This results in an increase of the ligand field around the iron(II) centers, which undergo spin crossover to the diamagnetic LS state. As the pressure increases, the number of paramagnetic centers in the cubic lattice decreases, as do the net magnetization and the critical temperature of the material. We now describe a complete magnetic and structural characterization of this process using different spectroscopic techniques, including soft X-ray absorption spectroscopy (XAS) and magnetic circular dichroism (XMCD). The phenomenon is compared to the "intrinsic" spin-crossover process $\mathrm{Cr}^{\mathrm{III}}-$ $\mathrm{C} \equiv \mathrm{N}-\mathrm{Fe}^{\mathrm{II}}(\mathrm{HS}) \rightarrow \mathrm{Cr}^{\mathrm{II}}-\mathrm{C} \equiv \mathrm{N}-\mathrm{Fe}^{\mathrm{II}}(\mathrm{LS})$ recently discovered by Ohkoshi and co-workers in the analogous compound $\mathrm{CsFe}\left[\mathrm{Cr}(\mathrm{CN})_{6}\right] \cdot 1.3 \mathrm{H}_{2} \mathrm{O}$. ${ }^{41}$ Some points concerning the mechanism of isomerization and the basis of its reversible character are also discussed.

\section{Experimental Section}

Synthesis of $\mathbf{K}_{\mathbf{0 . 4}} \mathrm{Fe}_{4}\left[\mathrm{Cr}(\mathrm{CN})_{\mathbf{6}}\right]_{2.8} \cdot \mathbf{1 6 H}_{\mathbf{2}} \mathrm{O}$ (1). Aqueous $50 \%$ ethanol solutions of potassium hexacyanochromate(III) (15 mg, $0.048 \mathrm{mmol}$ ) and iron(II) perchlorate (18 $\mathrm{mg}, 0.072 \mathrm{mmol})$ were allowed to diffuse in an $\mathrm{H}$-tube $(45 \mathrm{~mL}$ total volume). After 3 weeks, red cubic single crystals of $\mathbf{1}$ appeared. Yield: 15-30\%. IR $\left(\mathrm{KBr}, \mathrm{cm}^{-1}\right): 3430(\mathrm{O}-\mathrm{H}), 2160\left(\mathrm{Cr}^{\mathrm{III}} \mathrm{C} \equiv \mathrm{NFe}^{\mathrm{II}}\right), 2098$ $\left(\mathrm{Cr}^{\mathrm{III}} \mathrm{N} \equiv \mathrm{CFe}^{\mathrm{II}}\right), 1612(\mathrm{O}-\mathrm{H}), 485\left(\mathrm{Cr}^{\mathrm{III}}-\mathrm{CN}\right)$. Anal. Calcd for $\mathrm{K}_{0.4} \mathrm{Fe}_{4}\left[\mathrm{Cr}(\mathrm{CN})_{6}\right]_{2.8} \cdot 16 \mathrm{H}_{2} \mathrm{O}: \mathrm{C}, 18.18 ; \mathrm{H}, 2.91 ; \mathrm{N}, 21.10$. Found: C, 19.16; H, 2.94; N, 19.26. Metal Anal.: Cr, 38.9; Fe, 55.6; K, 5.6. Found: $\mathrm{Cr}, 38.7 ; \mathrm{Fe}, 55.1 ; \mathrm{K}, 6.2$.

IR transmission measurements on $\mathrm{KBr}$ pellets were recorded at room temperature with a Nicolet Avatar 320 FT-IR spectropho-

(34) Bozoglian, F.; Gonzalez, G.; Martinez, M.; Queirolo, M.; Sienra, B. Inorg. Chim. Acta 2001, 318, 191-196.

(35) Rachford, A. A.; Petersen, J. L.; Rack, J. J. Inorg. Chem. 2005, 44, $8065-8075$.

(36) To, T. T.; Burnes, C. E.; Burkey, T. J. Organometallics 2004, 23, 2708-2714.

(37) Brown, D. B.; Shriver, D. F.; Schwartz, L. H. Inorg. Chem. 1968, 7, 77-83.

(38) House, J. E.; Bailar, J. C. Inorg. Chem. 1969, 8, 672-673.

(39) Reguera, E.; Bertrán, J. F.; Nuñez, L. Polyhedron 1994, 13, 16191624.

(40) Coronado, E.; Giménez-López, M. C.; Levchenko, G.; Romero, F. M.; García-Baonza, V.; Milner, A.; Paz-Pasternak, M. J. Am. Chem. Soc 2005, 127, 4580-4581.

(41) Kosaka, W.; Nomura, K.; Hashimoto, K.; Ohkoshi, S. J. Am. Chem. Soc. 2005, 127, 8590-8591. 
tometer in the range $4000-400 \mathrm{~cm}^{-1}$. CHN elemental analyses were carried out in a CE Instruments EA 1110 CHNS analyzer. The expected $\mathrm{Cr} / \mathrm{Fe}$ ratios were confirmed on a Philips ESEM X230 scanning electron microscope equipped with an EDAX DX-4 microsonde. Thermogravimetric measurements were carried out with a Mettler Toledo TGA/SDTA 851 apparatus over the temperature range $298-1173 \mathrm{~K}$ under a nitrogen atmosphere at a scan rate of $5 \mathrm{~K} \mathrm{~min}^{-1}$

Magnetic Measurements. Variable-temperature (1000 Oe applied field) and field-dependent $(T=2 \mathrm{~K})$ magnetization measurements were carried out in a Quantum Design MPMS Squid magnetometer. The same device was used in the ac susceptibility measurements at different frequencies of the oscillating field of 3.95 $\mathrm{G}$ amplitude. The sample was placed in a hydrostatic pressure cell made of hardened beryllium bronze with silicone oil as the transmitting medium. The cell could operate at pressures below $1300 \mathrm{MPa}$. The diameter and length of the cylindrically shaped sample holder were 1 and $8 \mathrm{~mm}$, respectively. Pressure was measured using the pressure dependence of the superconducting transition temperature of a built-in pressure sensor made of highpurity tin.

Raman Spectroscopy. Raman spectra were measured at room temperature using a sapphire anvil cell that has been described elsewhere. ${ }^{42}$ The samples were excited using the $488 \mathrm{~nm}$ line of an ILT air-cooled $\mathrm{Ar}^{+}$laser. The scattered radiation was spatially filtered and collected upon backscattering into an ISA HR460 spectrograph coupled to a liquid nitrogen-cooled CCD multichannel detector. Spectra were collected at a spectral resolution of $4 \mathrm{~cm}^{-1}$. The pressure on the sample was determined with an absolute uncertainty of $90 \mathrm{MPa}$ by measuring the shift of the Raman band of the microcrystalline diamonds.

Mössbauer Spectroscopy. Mössbauer measurements were carried out in a top-loaded liquid helium cryostat over the temperature range $5-300 \mathrm{~K}$ at pressures of up to $\sim 50 \mathrm{GPa}$ using a ${ }^{57} \mathrm{Co}(\mathrm{Rh})$ point source. Samples were loaded into a miniature opposing-plates diamond anvil cell. The initial dimensions of the sample cavities in the Re gasket were $250 \times 35 \mu \mathrm{m}$. Typically, $\sim 24 \mathrm{~h}$ was required for the acquisition of each Mössbauer spectrum. The final spectra were analyzed using least-squares-fitting programs to obtain the hyperfine interaction parameters and component abundances.

Single-Crystal X-ray Diffraction Data Collection and Structure Determination. Crystal data for 1: $\mathrm{C}_{16.86} \mathrm{H}_{32} \mathrm{Cr}_{2.81} \mathrm{Fe}_{4} \mathrm{~K}_{0.45^{-}}$ $\mathrm{N}_{16.86} \mathrm{O}_{16}, M=1114.07$, cubic, $F m \overline{3} m, a=10.6459(4) \AA, V=$ $1206.56(8) \AA^{3}, Z=1, \rho_{\text {calc }}=1.533 \mathrm{Mg} \cdot \mathrm{m}^{-3}, \mu(\mathrm{Mo} \mathrm{K} \alpha)=1.885$ $\mathrm{mm}^{-1}$. A red cubic single crystal of 1 with dimensions $0.09 \times 0.09$ $\times 0.06 \mathrm{~mm}^{3}$ was mounted on the tip of a glass fiber. The data collection was carried out at $150 \mathrm{~K}$ on a Nonius Kappa CCD diffractometer $\left(6.62^{\circ}<2 \theta<61.14^{\circ}\right)$ equipped with a graphitemonochromatized Mo K $\alpha$ radiation source $(\lambda=0.71069 \AA)$. Of 13991 measured reflections, 143 were independent $\left(R_{\text {int }}=0.0999\right)$ and used to refine 23 parameters with zero restraints. A multiscan absorption correction based on equivalent reflections was applied to the data using the program SORTAV ${ }^{43}\left(T_{\max } / T_{\min }=0.891 / 0.825\right)$. The structure was solved by direct methods using SIR 97 software $^{44}$ and refined against $F^{2}$ with a full-matrix least-squares algorithm using SHELXL-97 ${ }^{45}$ and the WinGX (1.64) software package. ${ }^{46}$

It was impossible to distinguish between carbon and nitrogen atoms during the structural refinement; assignments were made on the basis of the distance from the atom to the bonded metal. The

(42) Baonza, V. G.; Taravillo, M.; Arencibia, A.; Cáceres, M.; Núñez, J. J. Raman Spectrosc. 2003, 34, 264-270.

(43) Blessing, R. H. J. Appl. Crvstallogr. 1997, 30, 421-426.

(44) Altomare, A.; Burla, M. C.; Camalli, M.; Cascarano, G.; Giacovazzo, C.; Guagliardi, A.; Moliterni, A. G. G.; Polidori, G.; Spagna, R. J. Appl. Crvstallogr. 1999, 32, 115-119.

(45) Sheldrick, G. M. SHELX-97: An Integrated System for Solving and Refining Crystal Structures from Diffraction Data; University of Göttingen: Göttingen, Germany, 1997.

(46) Farrugia, L. J. J. Appl. Crystallogr. 1999, 32, 837-838. shorter distance was assigned to the $\mathrm{Cr}-\mathrm{C}$ bond $[2.059(8) \AA]$. The occupancy factors obtained independently from the metal-content analysis were used in the structural refinement. The Fe occupancy was fixed to 1 , and therefore, the $\mathrm{K}$ occupancy factor was set to a value of 0.06. $\mathrm{C}$ and $\mathrm{N}$ occupancies were derived from that of $\mathrm{Cr}$ (0.70), using the fact that each $\mathrm{Cr}$ ion is surrounded by six cyanide anions. Moreover, the oxygen occupancy of the coordinated water $(\mathrm{O} 1,0.30)$ depends on the number of vacancies of $\left[\mathrm{Cr}(\mathrm{CN})_{6}\right]^{3-}$ anions in the unit cell. The best values of oxygen occupancy factors of the zeolitic water were fixed in the last cycles of refinement, taking into account the thermal parameters (O2, 0.08; O3, 0.13; O4, 0.06). $\mathrm{H}$ atoms from water molecules were neither observed in the Fourier map nor calculated. All of the other atoms were refined anisotropically, resulting in acceptable R-factors. Refinement converged at $\mathrm{R} 1=0.0499, \mathrm{wR} 2=0.1154$ for final $R[I>2 \sigma(I)]$ and at R1 $=0.0628, \mathrm{wR} 2=0.1211$ for all data. The $\mathrm{max} / \mathrm{min}$ residual peaks in the final difference map were +0.343 and -0.312 e $\AA^{-3}$, respectively. Details of crystal structure solution and refinement can be obtained from the Inorganic Crystal Structure Database (http://icsdweb.fiz-karlsruhe.de/index.php, entry number CSD-391283). The same structure has also been solved at room temperature $(293 \mathrm{~K})$. Details of this work are available in the Supporting Information.

Powder X-ray Diffraction. X-ray diffraction patterns of sets of crystals of $\mathbf{1}$ and MS (obtained after treatment of $\mathbf{1}$ to a pressure of $1200 \mathrm{MPa}$ for $503 \mathrm{~h}$ ) were collected at ambient conditions on a Bruker D8 Advance diffractometer equipped with a $\mathrm{Cu} \mathrm{K} \alpha$ rotating anode $(\lambda=1.5418 \AA)$. Both samples were placed in glass capillary tubes, and data were recorded over the range $5^{\circ}<2 \theta<80^{\circ}$ at $3 \mathrm{~s}$ per step, with angular steps of $0.03^{\circ}$ for $\mathbf{1}$ and $0.05^{\circ}$ for MS. Crystals of $\mathbf{1}$ were placed in a $0.5 \mathrm{~mm}$ glass capillary tube, whereas for MS a $0.1 \mathrm{~mm}$ glass capillary tube was used. The capillary tube was rotated during data collection. In both cases, the X-ray source was set at $40 \mathrm{kV}$ and $40 \mathrm{~mA}$.

XAS and XMCD Experiments at the $\mathrm{Cr}$ and $\mathrm{Fe} \mathrm{L}_{2,3}$ Edges. The X-ray polarized absorption and circular dichroism spectra were measured at the ID08 beamline of the European Synchrotron Radiation Facility (Grenoble, France) under 16-bunch ring operation $(80 \mathrm{~mA}$ at $6 \mathrm{GeV})$. The radiation was monochromatized with the use of a Dragon-type spherical grating monochromator. A circular polarization of the beam with $\sim 100 \%$ polarization rate was obtained by the use of an APPLE II undulator. Spectra were recorded in total electron yield mode with spectral resolutions of 0.2 and 0.1 $\mathrm{eV}$ at the $\mathrm{Fe}$ and $\mathrm{Cr}$ edges, respectively. The absorption spectra were normalized to the incident intensity, which was measured by means of a gold grid located just before the sample but far enough away from it to be insensitive to variations in the applied magnetic field. The base pressure in the chamber during the measurements was $\sim 5 \times 10^{-10}$ mbar. Measurements were performed at $10 \mathrm{~K}$ and in an applied magnetic field $H$ of $\pm 5 \mathrm{~T}$. The direction of the incident beam was parallel to the magnetic field, and both were perpendicular to the sample surface. In order to minimize the effects of field inhomogeneity, we first fixed $H$ at $+5 \mathrm{~T}$ and switched the polarization of the beam parallel and antiparallel to the magnetic field. Next, the same procedure was repeated with $H$ fixed at -5 T. In total, four spectra were registered with the magnetic field parallel (antiparallel) to the propagation vector of the photons and averaged to give a spectrum labeled $\sigma^{\uparrow \uparrow}\left(\sigma^{\uparrow \downarrow}\right)$. In the following, XAS spectra refer to the sum of these two spectra $\left(\sigma^{\Uparrow \uparrow}+\sigma^{\uparrow \downarrow}\right)$. The XMCD signal is the difference between the two spectra $\left(\sigma^{\Uparrow \uparrow}-\sigma^{\uparrow \downarrow}\right)$. The experimental data were corrected for $\mathrm{L}_{3}$ and $\mathrm{L}_{2}$ jumps by the use of a step function. The samples investigated were finely ground solid materials.

LFM Calculations. Simulations of XAS and XMCD spectra at the $\mathrm{L}_{2,3}$ edges of $\mathrm{Fe}$ and $\mathrm{Cr}$ were performed for the different samples using TT-Multiplets software, which is based on the ligand-field 


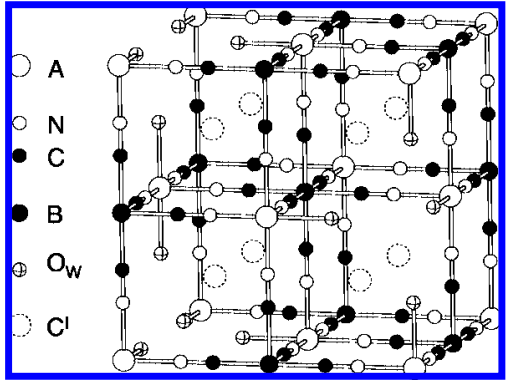

Figure 1. View of the unit cell of a Prussian blue analogue having $\mathrm{A} / \mathrm{B}=$ $3 / 2$ stoichiometry, showing a random distribution of $\left[\mathrm{B}(\mathrm{CN})_{6}\right]^{3-}$ vacancies and $\mathrm{A}^{2+}$-coordinated water molecules.

multiplet (LFM) model implemented by Thole, ${ }^{47}$ the atomic theory developed by Cowan, ${ }^{48}$ and the crystal-field interactions model developed by Butler. ${ }^{49}$ This approach includes both electronic Coulomb interactions and spin-orbit coupling for each subshell. The interelectronic repulsions were introduced through Slater integrals that were reduced by a factor $\kappa$ that takes into account the partial covalent character of the metal-ligand bonds. The values of the spin-orbit coupling constants $\zeta_{2 \mathrm{p}}$ and $\zeta_{3 \mathrm{~d}}$ were taken as $100 \%$ of the free-ion values (see the Supporting Information). The calculations included all possible one-electron transitions between the $2 \mathrm{p}^{6} 3 \mathrm{~d}^{n}$ ground state and the $2 \mathrm{p}^{5} 3 \mathrm{~d}^{n+1}$ excited state. To model charge-transfer effects, which play an important role in cyanometalates, the calculations used two-configuration initial states. The $\sigma$-bonding effects were taken into account by addition of LMCT configurations $\left(d^{6}+d^{7} \underline{L}\right.$ for $\mathrm{Fe}^{2+}$ and $\mathrm{d}^{5}+\mathrm{d}^{6} \underline{\mathrm{L}}$ for $\mathrm{Fe}^{3+}$, where $\underline{\mathrm{L}}$ means ligand hole), while $\pi$ back-bonding was introduced by using MLCT configurations $\left(d^{3}+d^{2} L\right.$ for $\mathrm{Cr}^{3+}$ and $d^{6}+d^{5} L$ for $\left.\mathrm{Fe}^{2+}\right)$. The charge-transfer energies EG2 and EF2 are defined as the differences between the energy values of the centers of the multiplet structures for the ground and final states, respectively. The simulated signals were broadened by both Lorentzian and Gaussian functions in order to account for lifetime and instrumental broadening, respectively. ${ }^{50}$

\section{Results and Discussion}

Crystal Growth, Structure, and Characterization of 1. Previously reported preparations of $\mathrm{Fe}_{3}\left[\mathrm{Cr}(\mathrm{CN})_{6}\right]_{2}$ from aqueous solutions of the starting materials $\left[\mathrm{Fe}\left(\mathrm{H}_{2} \mathrm{O}\right)_{6}\right]^{2+}$ and $\left[\mathrm{Cr}(\mathrm{CN})_{6}\right]^{3-}$ yielded crystalline powders, probably of submicrometer size. ${ }^{37-39}$ We obtained cubic single crystals $(\sim 70 \mu \mathrm{m}$ side length) of $\mathbf{1}$ by slow diffusion of $\left[\mathrm{Fe}\left(\mathrm{H}_{2} \mathrm{O}\right)_{6}\right]\left(\mathrm{ClO}_{4}\right)_{2}$ and $\mathrm{K}_{3}\left[\mathrm{Cr}(\mathrm{CN})_{6}\right]$ solutions in a 1:1 water/ethanol mixture. Compound 1 crystallizes in the $F m \overline{3} m$ space group. Its structure is typical of a Prussian blue analogue (Figure 1), with $\mathrm{Fe}^{2+}$ and $\mathrm{Cr}^{3+}$ cations sitting at the $(0,0,0)$ and $(1 / 2,1 / 2,1 / 2)$ special positions, respectively, of a face-centered cubic unit cell with a side length of 10.6459(4) $\AA$. Cyanide ligands bridge the metal ions in a linear arrangement, giving rise to a three-dimensional $\mathrm{Fe}^{\mathrm{II}}$ $\left[\mathrm{Cr}^{\mathrm{III}}(\mathrm{CN})_{6}\right]$ structure. In order to satisfy electroneutrality, approximately one-third of the $\left[\mathrm{Cr}(\mathrm{CN})_{6}\right]^{3-}$ sites are vacant, and their neighboring $\mathrm{Fe}^{2+}$ cations are bonded to water molecules to achieve sixfold coordination. The random distribution of $\left[\mathrm{Cr}(\mathrm{CN})_{6}\right]^{3-}$ vacancies and coordinated water molecules

(47) Thole, B. T.; van der Laan, G.; Fuggle, J. C.; Sawatzky, G. A.; Karanatak, R. C.; Esteva, J.-M. Phys. Rev. B 1985, 32, 5107-5118.

(48) Cowan, R. D. The Theory of Atomic Structure and Spectra; University of California Press: Berkeley, CA, 1981.

(49) Butler, P. H. Point Group Symmetry, Applications, Methods and Tables; Plenum Press: New York, 1981.

(50) deGroot, F. M. F.; Fuggle, J. C.; Thole, B. T.; Sawatzky, G. A. Phvs. Rev. B 1990, 41, 928-938. yields a disordered structure. Further, the system accommodates some potassium cations and zeolitic water molecules in the cavities. These two points make it difficult to ascertain the formula of the compound from the X-ray diffraction study. EDAX measurements and $\mathrm{CHN}$ analysis suggest the formula $\mathrm{K}_{0.4} \mathrm{Fe}_{4}\left[\mathrm{Cr}(\mathrm{CN})_{6}\right]_{2.8} \square_{1.2} \cdot 16 \mathrm{H}_{2} \mathrm{O}$ for $\mathbf{1}$, where $\square$ represents a $\left[\mathrm{Cr}(\mathrm{CN})_{6}\right]^{3-}$ vacancy, and the occupancies of all of the atoms were fixed in order to satisfy this unit cell content. This gives an average of 4.2 cyanide anions and 1.8 water molecules in the iron coordination sphere. The $\mathrm{Fe}^{2+}$-ligand bond distances are characteristic of an HS configuration, with an $\mathrm{Fe}-\mathrm{N}$ distance of 2.077(15) $\AA$.

The structure solved at room temperature shows a cubic cell parameter of $10.6720(2) \AA$, evidencing a small thermal expansion. The value of the $\mathrm{Fe}-\mathrm{N}$ distance $[2.092(11) \AA]$ is very similar to that obtained from the low-temperature data. This excludes any thermally induced structural change in the 293- $150 \mathrm{~K}$ range.

The cyanide region in the IR spectra of Prussian blue analogues is very sensitive to the oxidation state of the bonded metal ions. ${ }^{51,52}$ For instance, the IR spectrum of $\mathrm{Fe}_{3}\left[\mathrm{Cr}^{\mathrm{III}}(\mathrm{CN})_{6}\right]_{2}$ shows a single band at $2168 \mathrm{~cm}^{-1}$, whereas its isomer $\mathrm{Cr}_{4}\left[\mathrm{Fe}^{\mathrm{II}}(\mathrm{CN})_{6}\right]_{3}$ absorbs at $2092 \mathrm{~cm}^{-1}$. Compound 1 exhibits two bands located at 2160 and $2098 \mathrm{~cm}^{-1}$. The high-frequency band corresponds to the $\mathrm{Cr}^{\mathrm{III}}-\mathrm{C} \equiv \mathrm{N}-\mathrm{Fe}^{\mathrm{II}}$ configuration, while the weak low-frequency band can be assigned to isomerized or "cyanide-flipped" $\mathrm{Cr}^{\mathrm{III}}-\mathrm{N} \equiv \mathrm{C}-\mathrm{Fe}^{\mathrm{II}}$ moieties. The $2098 \mathrm{~cm}^{-1}$ peak is absent in the material prepared from the same solutions by fast precipitation, indicating that cyanide exchange can take place in solution under slow-diffusion conditions. The extent of isomerization was determined through the univariant calibration technique, using pure $\mathrm{Fe}_{3}\left[\mathrm{Cr}(\mathrm{CN})_{6}\right]_{2}$ and $\mathrm{Cr}_{4}\left[\mathrm{Fe}(\mathrm{CN})_{6}\right]_{3}$ as standards. The relative content of cyanide-flip defects in the material is very low $(<0.9 \%)$ but could be determined because of the extreme sensitivity of the IR spectra to the presence of $\mathrm{Cr}^{\mathrm{III}}-\mathrm{N} \equiv \mathrm{C}-\mathrm{Fe}^{\mathrm{II}}$ units.

The magnetic behavior of crystals of $\mathbf{1}$ is similar to that previously observed in thin films and powder samples without isomerization. ${ }^{53}$ The reciprocal magnetic susceptibility $\left(\chi^{-1}\right)$ follows a Curie-Weiss law in the high-temperature region with $\theta=+27 \mathrm{~K}$, indicating the presence of short-range ferromagnetic interactions. The $\chi T$ product at $300 \mathrm{~K}\left(18.2 \mathrm{emu} \mathrm{K} \mathrm{mol}^{-1}\right)$ is higher than the "spin-only" value $\left(15.9 \mathrm{emu} \mathrm{K} \mathrm{mol}{ }^{-1}\right)$ calculated for four $S=2\left(\mathrm{Fe}^{2+}\right)$ and $2.8 S=3 / 2\left(\mathrm{Cr}^{3+}\right)$ noninteracting spins. This difference is primarily attributed to the $\mathrm{Fe}^{2+}$ orbital contribution. The temperature dependence of the susceptibility $(M / H)$ shows a continuous increase of the signal upon cooling (Figure 2). Below $25 \mathrm{~K}, \mathrm{M} / \mathrm{H}$ increases more abruptly and reaches a (field-dependent) saturation value at lower temperatures, pointing to the presence of ferromagnetic order.

A critical temperature $\left(T_{\mathrm{C}}\right)$ of $19.5 \mathrm{~K}$ was estimated from a first derivative $[\partial M / \partial T=f(T)]$ plot. However, a more precise determination of $T_{\mathrm{C}}$ was obtained from ac susceptibility measurements (Figure 3). The onset of the out-of-phase component gives a value of $T_{\mathrm{C}}=18.5 \mathrm{~K}$. Both the real $\left(\chi^{\prime}\right)$ and imaginary $\left(\chi^{\prime \prime}\right)$ components of the ac susceptibility exhibit frequency dependences that are weaker than those observed in

(51) Nakamoto, K. Infrared and Raman Spectra of Inorganic and Coordination Compounds; John Wiley \& Sons: New York, 1986.

(52) Socrates, G. Infrared Characteristic Group Frequencies. Tables and Charts; John Wiley \& Sons: New York, 1994.

(53) Ohkoshi, S.; Einaga, Y.; Fujishima, A.; Hashimoto, K. J. Electroanal. Chem. 1999, 473, 245-249. 


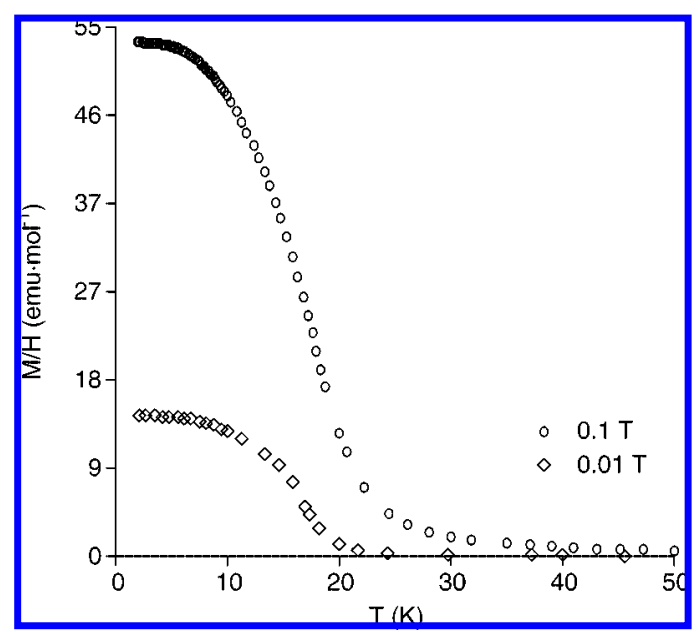

Figure 2. Thermal variation of the $M / H$ ratio of $\mathbf{1}$ in applied fields of $(O)$ 0.1 and $(\diamond) 0.01 \mathrm{~T}$.

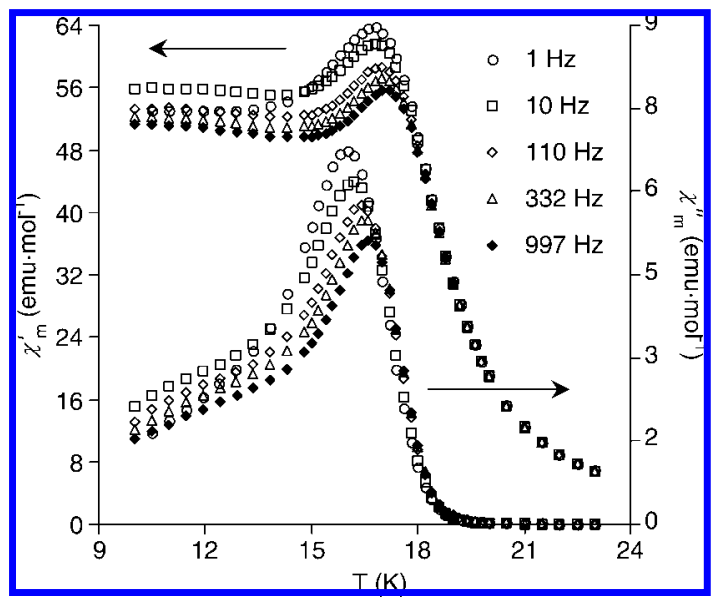

Figure 3. Temperature dependence of the ac magnetic susceptibility of $\mathbf{1}$ at different frequencies.

superparamagnets and other materials showing thermally activated relaxation processes. Indeed, the frequency dependence of the maximum observed in the $\chi^{\prime \prime}=f(T)$ curve obeys the following power law, which is characteristic of spin glasses with strong interactions between magnetic moments: ${ }^{54}$

$$
\tau=\tau_{0}\left(\frac{T_{\mathrm{g}}}{T_{\max }-T_{\mathrm{g}}}\right)^{z v}
$$

where the relaxation time $\tau$ is the inverse of the frequency of the oscillating field, $\tau_{0}$ is the pre-exponential factor, $z v$ is the critical exponent, $T_{\mathrm{g}}$ is the spin-glass temperature, and $T_{\max }$ is the temperature of the maximum. The best-fit parameters are the following: $T_{\mathrm{g}}=15.6 \mathrm{~K} ; \tau_{0}=2.7 \times 10^{-11} \mathrm{~s}^{-1} ; z v=6.5$. The value of the critical exponent lies in the expected range for spin glasses $(4<z v<12)$. Furthermore, the relative variation of $T_{\max }$ per decade of frequency, $\Delta T_{\max } /\left[T_{\max } \Delta \log (v)\right]$ $=0.015$, is smaller than 0.06 , as expected for a canonical spin glass. It is worth noting that $T_{\mathrm{g}}<T_{\mathrm{C}}$. This behavior has been observed previously in other Prussian blue analogues and is termed "reentrant" because the magnetically ordered state reenters a glassy "disordered" state at lower temperatures. ${ }^{55}$ The structural disorder, which is typical of these compounds, together

(54) Mydosh, J. A. Spin Glasses: An Experimental Introduction; Taylor \& Francis: London, 1993

(55) Buschmann, W. E.; Miller, J. S. Inorg. Chem. 2000, 39, 2411-2421.

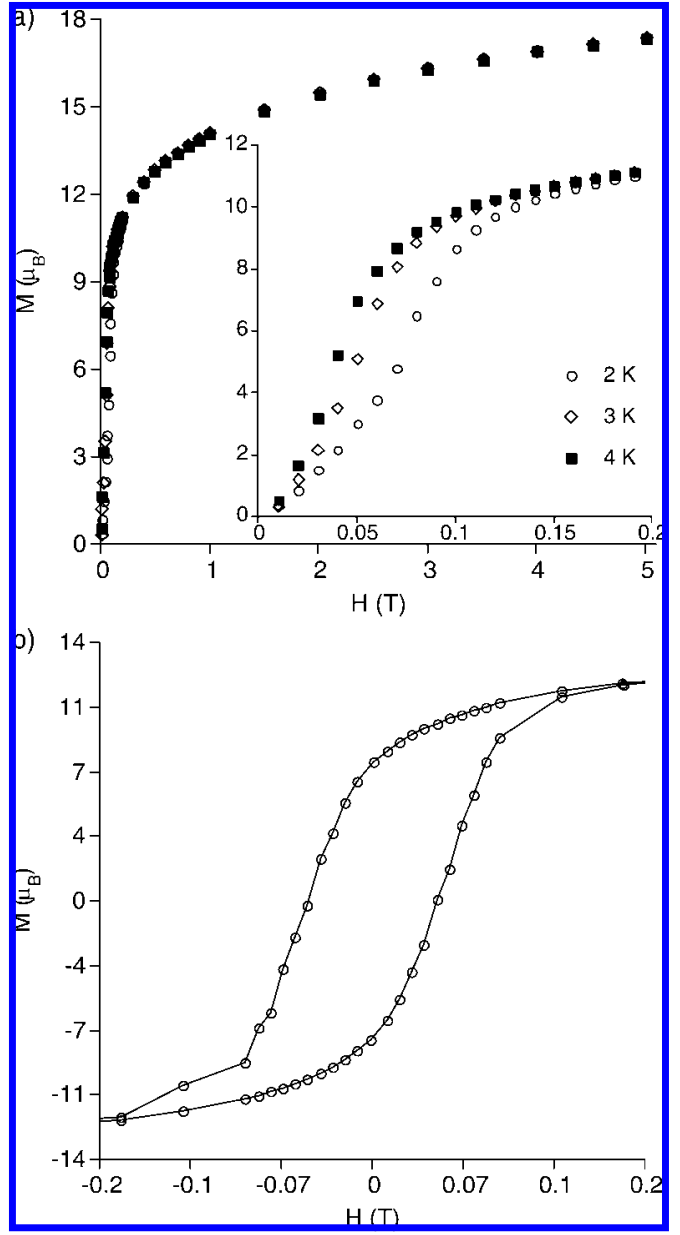

Figure 4. (a) Field dependence of the magnetization of $\mathbf{1}$ at different temperatures below $T_{\mathrm{C}}$. The inset shows the low-field region. (b) Hysteresis plot for $\mathbf{1}$ at $T=2 \mathrm{~K}$.

with the anisotropy of the local magnetic moments $\left(\mathrm{Fe}^{2+}\right)$ and exchange interactions can result in the formation of uncompensated magnetic moments that contribute to the entropy of the system at lower temperatures, giving rise to reentrance.

Magnetization-versus-field plots at different temperatures below $T_{\mathrm{C}}$ (Figure $4 \mathrm{a}$ ) show a steep increase in the low-field region. The magnetization reaches $11 \mu_{\mathrm{B}}$ at $0.2 \mathrm{~T}$, which is greater than the value expected for antiparallel alignment of the spins $\left(9 \mu_{\mathrm{B}}\right)$. At the highest field of the experiment $(5 \mathrm{~T})$, the magnetization $\left(18 \mu_{\mathrm{B}}\right)$ is still far from the saturation value $\left(24.4 \mu_{\mathrm{B}}\right)$. This divergence might be due to the local anisotropy of $\mathrm{Fe}^{2+}$ ions having a strong orbital contribution to the magnetic moment. Further, the spin-glass behavior is confirmed by the presence of a sigmoidal variation of the magnetization at very low fields (Figure $4 \mathrm{a}$ inset). The hysteresis plot at $2 \mathrm{~K}$ shows a very small coercive field $\left(H_{\mathrm{c}}\right)$ of $0.053 \mathrm{~T}$ (Figure $4 \mathrm{~b}$ ). Overall, the results confirm the ferromagnetic character of $\mathbf{1}$.

Pressure-Induced Magnetic Switching. The temperature dependence of the magnetization at different pressures was measured under isotropic conditions (Figure 5). As the pressure increases from ambient conditions up to $1200 \mathrm{MPa}, T_{\mathrm{C}}$ shifts down from 18.5 to $13 \mathrm{~K}$, and the low-temperature $(2 \mathrm{~K})$ magnetization decreases to half its original value. The decrease of the net magnetic moment upon compression can also be observed in the field dependence of the magnetization (Figure 6 ). The magnetization at the highest field of the experiment (5 T) decreases from $17.8 \mu_{\mathrm{B}}$ at room pressure to $9.8 \mu_{\mathrm{B}}$ after 


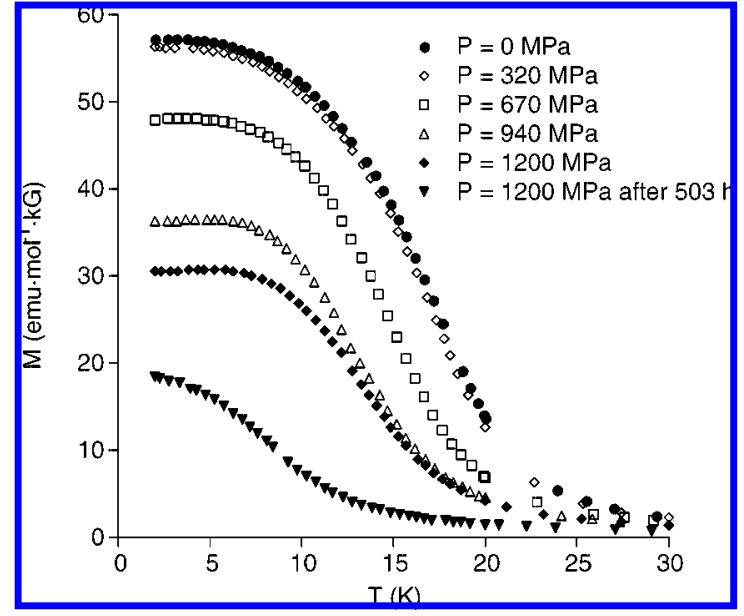

Figure 5. Thermal dependence of the magnetization of 1 (magnetic field $=0.1 \mathrm{~T})$ at different applied pressures.

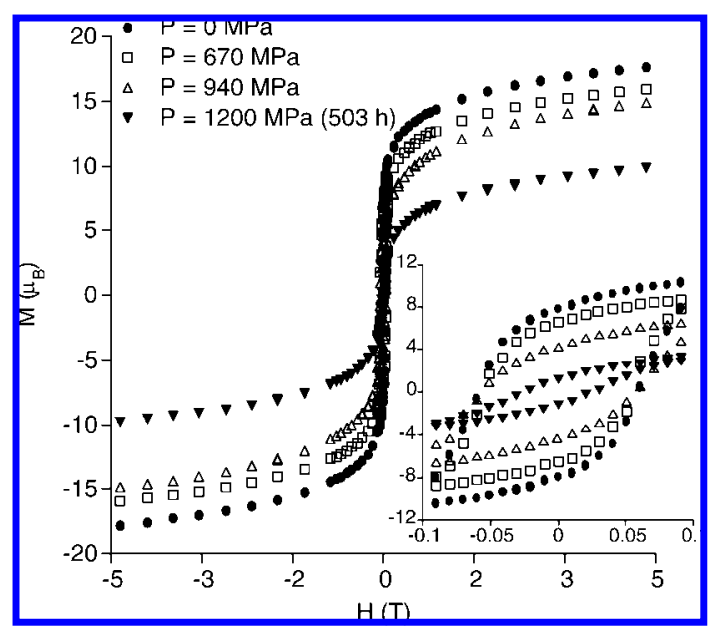

Figure 6. Field dependence of the magnetization of $\mathbf{1}(T=2 \mathrm{~K})$ at different applied pressures. The inset shows the low-field region.

prolonged treatment at $1200 \mathrm{MPa}$. With an assumed contribution of $4 \mu_{\mathrm{B}}$ per $\mathrm{Fe}$ (II) center to the saturated magnetization, the observed $8 \mu_{\mathrm{B}}$ decrease suggests the presence of two $\mathrm{Fe}^{2+}$ cations per formula unit in the low-spin configuration. This means that $50 \%$ of the $\mathrm{Cr}^{\mathrm{II}}-\mathrm{C} \equiv \mathrm{N}-\mathrm{Fe}^{\mathrm{II}}$ units have undergone isomerization to the $\mathrm{Cr}^{\mathrm{III}}-\mathrm{N} \equiv \mathrm{C}-\mathrm{Fe}^{\mathrm{II}}$ form. It should be noted that at all of the pressures studied, the magnetization at $5 \mathrm{~T}$ is far from saturation. However, our calculation is still valid because the slope of the magnetization curve at high field is almost constant and independent of pressure. At least, the $50 \%$ value can be considered as an upper limit for the degree of isomerization. The compound exhibits magnetic hysteresis loops with remnant magnetization values that are pressure-dependent (Table 1). At moderate pressures, the coercive field (Figure 6 inset) remains practically constant and equal to the value obtained under room conditions. After application of an external pressure of 1200 MPa for several weeks, the coercive field decreases to a value of $0.025 \mathrm{~T}$. This means that at moderate pressures, the magnetic domains are unaffected by the pressure-induced changes in the material. Only under extreme conditions can the new structural domains that appear after pressure treatment be large enough to affect the domain dynamics and the value of the coercive field.

Temperature-dependent ac susceptibility measurements also give evidence of the change of the magnetic properties of $\mathbf{1}$
Table 1. Pressure Dependence of the Magnetic Ordering Parameters of 1

\begin{tabular}{llllll}
\hline & $0 \mathrm{MPa}$ & $670 \mathrm{MPa}$ & $940 \mathrm{MPa}$ & $1200 \mathrm{MPa}$ & $1200 \mathrm{MPa}^{f}$ \\
\hline$M_{2 \mathrm{~K}}{ }^{a}$ & 57.22 & 47.98 & 36.26 & 30.49 & 18.41 \\
$T_{\mathrm{C}}(\mathrm{K})^{b}$ & 18.5 & 16 & 13.5 & 13 & 7.5 \\
$M_{\text {sat }}{ }^{c}$ & 17.8 & 15.9 & 14.8 & & 9.8 \\
$H_{\mathrm{c}}(\mathrm{T})^{d}$ & 0.058 & 0.054 & 0.057 & & 0.025 \\
$M_{\text {rem }}{ }^{e}$ & 7.89 & 6.52 & 4.21 & & 1.16
\end{tabular}

${ }^{a}$ Magnetization (emu $\left.\mathrm{mol}^{-1} \mathrm{kG}\right)$ measured at $2 \mathrm{~K}$ in a $0.1 \mathrm{~T}$ magnetic field. ${ }^{b}$ Critical temperature. ${ }^{c}$ Magnetization (emu mol ${ }^{-1} \mathrm{kG}$ ) measured at $2 \mathrm{~K}$ in a $5 \mathrm{~T}$ magnetic field. ${ }^{d}$ Coercive field at $2 \mathrm{~K}$. ${ }^{e}$ Remnant magnetization (emu mol ${ }^{-1} \mathrm{kG}$ ) at $2 \mathrm{~K} .^{f}$ After $503 \mathrm{~h}$.

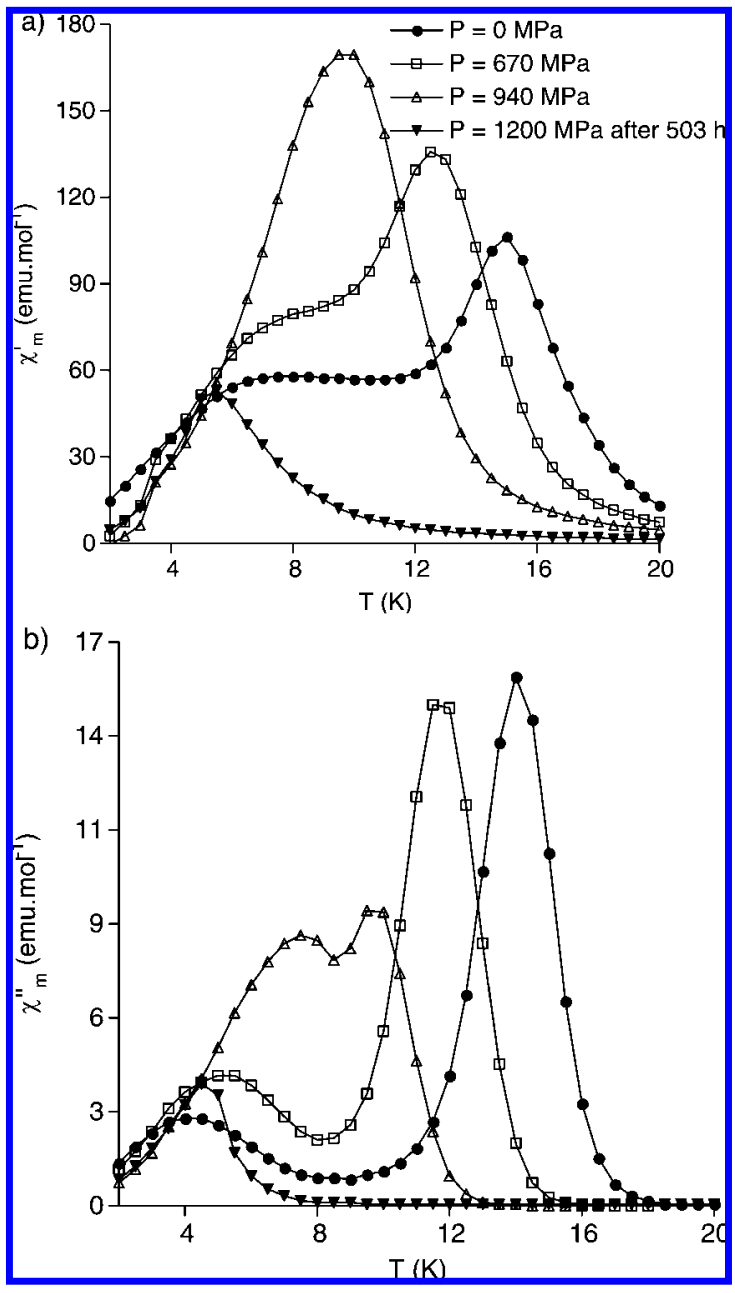

Figure 7. Thermal variation of the (a) real and (b) imaginary parts of the ac magnetic susceptibility of $\mathbf{1}$ at different pressures. The frequency of the oscillating field was $1 \mathrm{~Hz}$.

under external pressure. At ambient conditions, the thermal variation of the real component $\left(\chi^{\prime}\right)$ of the ac susceptibility (Figure 7a) exhibits a maximum near the ordering temperature and a shoulder at lower temperatures. After pressure treatment at 670 and $940 \mathrm{MPa}$, the two features gain intensity and collapse to a single peak. However, after prolonged treatment at 1200 $\mathrm{MPa}$, the signal dramatically loses its intensity, and only the low-temperature feature is present. Similar observations apply to the description of the imaginary component $\left(\chi^{\prime \prime}\right)$. At room pressure, the $\chi^{\prime \prime}=f(T)$ plot shows an onset at $T_{\mathrm{C}}=18.5 \mathrm{~K}$ together with a second peak that appears below $7 \mathrm{~K}$ (Figure $7 b$ ). As already mentioned, the high-temperature peak corresponds to ferromagnetic ordering of the material. The low- 


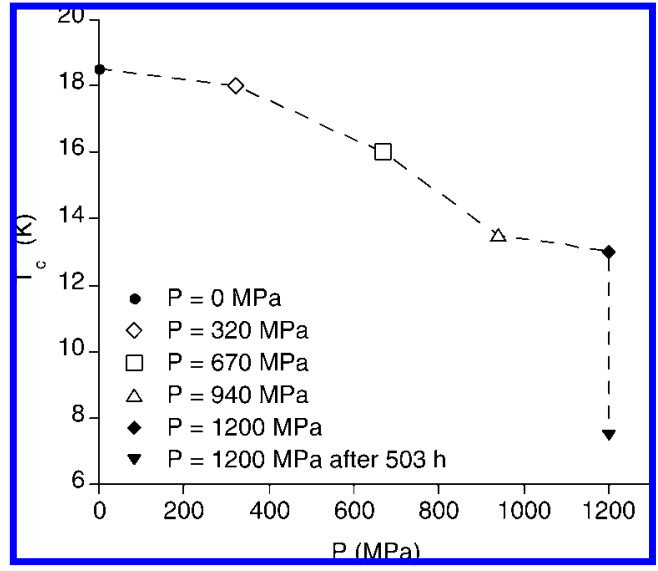

Figure 8. Pressure dependence of the critical temperature of $\mathbf{1}$.

temperature feature comes from the random inhomogeneous distribution of $\left[\mathrm{Cr}(\mathrm{CN})_{6}\right]^{3-}$ vacancies and $\mathrm{Cr}^{\mathrm{III}}-\mathrm{N} \equiv \mathrm{C}-\mathrm{Fe}^{\mathrm{II}}$ defects. There is a finite probability of finding some structural domains where the spin correlation is not sufficient to achieve long-range order. In these clustered regions, a (super)paramagnetic behavior is in principle expected. However, the presence of next-nearest-neighbor interactions could also drive magnetic ordering in these regions at lower temperatures. For instance, the archetypal Prussian blue, $\mathrm{Fe}^{\mathrm{III}}{ }_{4}\left[\mathrm{Fe}^{\mathrm{II}}(\mathrm{CN})_{6}\right]_{3}$, which contains more than $40 \%$ diamagnetic iron(II) centers, orders ferromagnetically at $T_{\mathrm{C}}=5.5 \mathrm{~K} .^{56}$ As the number of isomerized $\mathrm{Cr}^{\mathrm{III}}-\mathrm{N} \equiv \mathrm{C}-\mathrm{Fe}^{\mathrm{II}}$ moieties increases under pressure, $T_{\mathrm{C}}$ decreases, but the low-temperature feature becomes more important and shifts to higher temperatures at an average rate of $\mathrm{d} T /$ $\mathrm{d} P=4 \mathrm{~K} \mathrm{GPa}^{-1}$. These two aspects respectively indicate a decrease in the number of magnetically active centers and a strengthening of the next-nearest-neighbor magnetic interactions existing in the system, consistent with a stronger overlap between magnetic orbitals. Indeed, a quasi-linear increase of the Curie temperature with pressure $\left(\mathrm{d} T_{\mathrm{C}} / \mathrm{d} P=1 \mathrm{~K} \mathrm{GPa}^{-1}\right)$ has been reported for the less compressible compound $\mathrm{CsFe}$ $\left[\mathrm{Cr}(\mathrm{CN})_{6}\right]\left(T_{\mathrm{C}} \approx 8-9 \mathrm{~K}\right)$, indicating that interactions between $\mathrm{Cr}^{3+}$ ions are reinforced under the application of pressure. ${ }^{57}$

As already observed for the fresh material, both of the susceptibility components are frequency-dependent (see the Supporting Information). As the frequency increases, the outof-phase signals become more important and shift to higher temperature values.

A $T_{\mathrm{C}}=f(P)$ plot (Figure 8) reveals that $T_{\mathrm{C}}$ remains practically unaltered upon application of pressures up to $320 \mathrm{MPa}$, then decreases at a constant rate over the pressure range 320-940 $\mathrm{MPa}$ to reach a value of $13.5 \mathrm{~K}$, and finally undergoes a further depletion to $T_{\mathrm{C}}=7.5 \mathrm{~K}$ after a long treatment $(503 \mathrm{~h})$ at the maximum pressure reached in the experiment.

It is worth pointing out that all of the measurements in this pressure-dependent (dc and ac) magnetic susceptibility study were performed on the same sample. After a measurement at a given pressure of interest, the sample was decompressed, and the pressure was then increased to the value used in the next measurement. The $M=f(T)$ plots recorded after each decompression were virtually undistinguishable from that obtained on the fresh material, confirming the reversibility of the process.

(56) Ito, A.; Suenaga, M.; Ono, K. J. Chem. Phys. 1968, 48, 3597-3599.

(57) Papanikolaou, D.; Kosaka, W.; Margadonna, S.; Kagi, H.; Ohkoshi, S.; Prassides, K. J. Phys. Chem. C 2007, 111, 8086-8091.

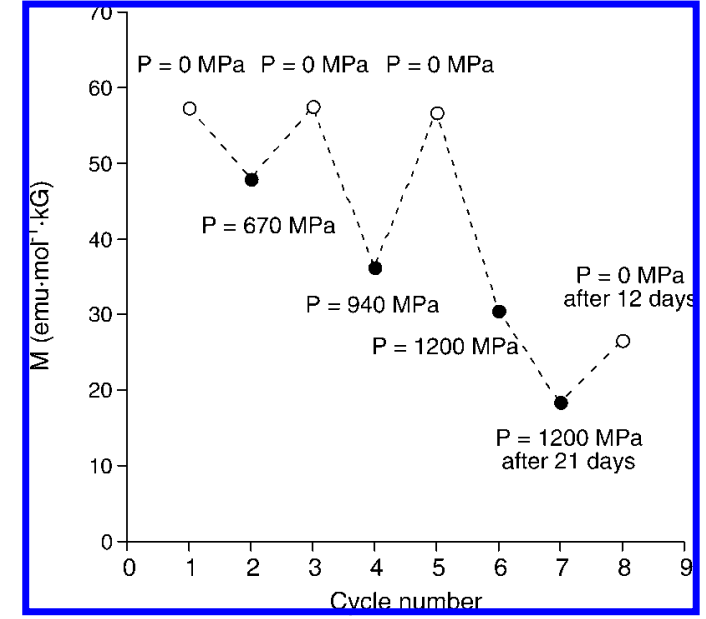

Figure 9. Reversibility plot showing changes in the magnetization of $\mathbf{1}$ at $2 \mathrm{~K}$ induced upon alternation of pressure application $(\mathbf{)})$ and release $(\mathrm{O})$.

Figure 9 plots the value of the magnetization at $2 \mathrm{~K}$ as the reversible parameter. When $P=670 \mathrm{MPa}$, the magnetization decreases by $16 \%$, after which pressure release restores the initial $M$ value. Increasing the pressure to $940 \mathrm{MPa}$ decreases $M$ by $\sim 37 \%$, and again, decompression confirms the complete reversibility of the process. However, under more severe conditions $(P=1200 \mathrm{MPa}$ for $503 \mathrm{~h}$ ), the magnetization irreversibly decreases by $68 \%$. After release of the pressure, a very slow recovery of $M$ (only a $21 \%$ increase of the signal after 12 days at ambient conditions) is observed. A metastable material suitable for further characterization can be thus obtained via this procedure. A study of the magnetic properties of a metastable sample subjected to single compression at $P=1200$ $\mathrm{MPa}$ during $500 \mathrm{~h}$ (see the Supporting Information) reveals ferromagnetic ordering below $T_{\mathrm{C}}=13 \mathrm{~K}$.

The kinetics of the transformation has been studied by magnetic techniques in the irreversible region (i.e., at $P=1200$ $\mathrm{MPa}$ ), where the change in the magnetic properties takes place in an appropriate time window. For this purpose, a fresh sample was subjected to this pressure, and the time dependence of the magnetic ordering parameters was measured. $M$-versus- $T$ curves at different times $t$ are plotted in Figure 10. The magnetization at $2 \mathrm{~K}\left(M_{2 \mathrm{~K}}\right)$ decreases exponentially from an initial value of $39.5 \mathrm{emu} \mathrm{mol}^{-1} \mathrm{kG}$ to a value of $23.6 \mathrm{emu} \mathrm{mol}^{-1} \mathrm{kG}$ at $t=$ $500 \mathrm{~h}$. This corresponds to a $40 \%$ decrease in the signal. The critical temperature of the material decreases from an initial value of $14.1 \mathrm{~K}$ to a value of $9.6 \mathrm{~K}$ at $t=500 \mathrm{~h}$. It is worthy of note that this latter value differs from that obtained for the sample used in the reversibility studies $\left(T_{\mathrm{C}}=7.5 \mathrm{~K}\right)$, evidencing a certain fatigue in the material. The $T_{\mathrm{C}}=f(t)$ curve (Figure 10 inset) follows an exponential law of the type $T_{\mathrm{C}}=A+B \mathrm{e}^{-t / \tau}$, where $A$ is the limiting $T_{\mathrm{C}}$ value at $t=\infty, A+B$ equals the $T_{\mathrm{C}}$ value at $t=0$, and $\tau$ is the relaxation time. The best-fit data affords the following values for the different parameters: $A=$ 9.5(3) $\mathrm{K} ; B=4.4(3) \mathrm{K}$, and $\tau=180(30) \mathrm{h}$.

In summary, the magnetic behavior of $\mathbf{1}$ under pressure indicates a structural transformation that involves a reduction in the magnetic moment and critical temperature of the material. In principle, the following processes can be envisaged (Scheme 1): (A) $\mathrm{Fe}^{2+}$ ("intrinsic") spin crossover, (B) linkage isomerization of the cyanide-metal bond with consequent spin change of $\mathrm{Fe}^{2+}$, and $(\mathrm{C})$ an electron-transfer reaction. We performed a thorough pressure-dependent structural characterization of the 


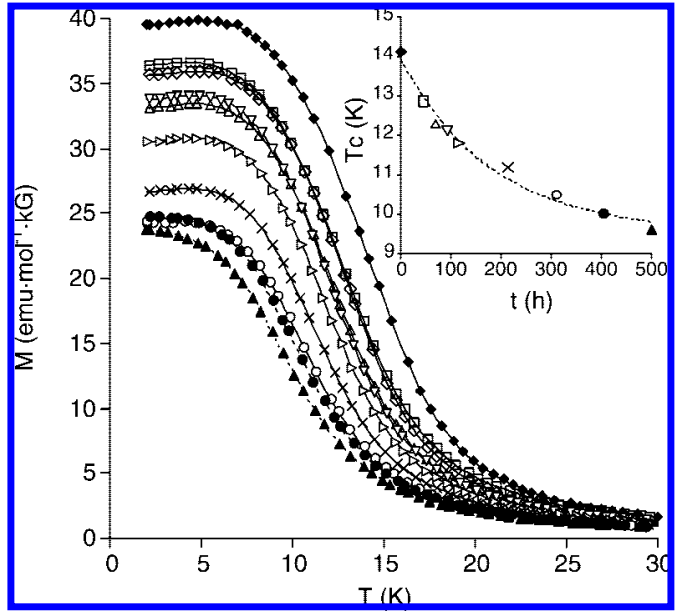

Figure 10. Thermal variation of the magnetization of $\mathbf{1}$ under an applied pressure of $1200 \mathrm{MPa}$ at different reaction times. Inset: time dependence of the critical temperature of $\mathbf{1}$.

\section{Scheme 1}

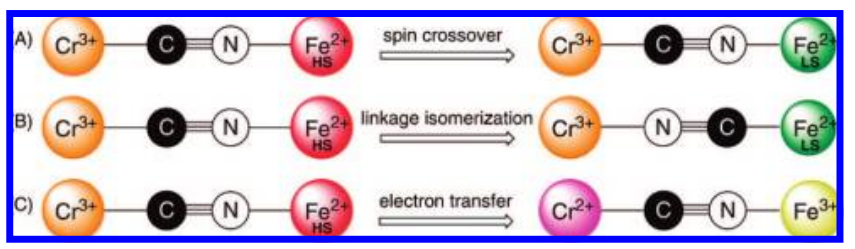

compound using different physical techniques in order to verify that its magnetic behavior originates from process $B$.

Pressure-Dependent Raman Spectroscopy. The IR and Raman spectra of metal cyanides have been studied in detail. ${ }^{58}$ As was pointed out earlier, the frequency of the stretching vibration of the cyanide ligand is quite sensitive to the oxidation state of the carbon-bonded metal ion. Process A, with no change in oxidation states, should proceed with a small shift of the $-\mathrm{C} \equiv \mathrm{N}-$ stretching frequency. Indeed, such a process has recently been induced by a temperature change in $\mathrm{CsFe}$ $\left[\mathrm{Cr}(\mathrm{CN})_{6}\right] \cdot 1.3 \mathrm{H}_{2} \mathrm{O}$, and a frequency shift of $7 \mathrm{~cm}^{-1}$ in the IR spectrum was reported. ${ }^{41}$ In contrast, processes $\mathrm{B}$ and $\mathrm{C}$, both of which involve a change in the oxidation state of the carbonbonded metal ion, should induce larger frequency shifts $(\sim 60$ $\mathrm{cm}^{-1}$ ), as expected from the weakening of the $\sigma$ bond as the metal oxidation state decreases.

Raman spectra of single crystals of $\mathbf{1}$ were recorded at different pressures (Figure 11a) in a sapphire anvil cell. At ambient pressure, the Raman frequencies closely resemble the IR data, showing two bands with quite different cross sections: the intense band is centered at $2164 \mathrm{~cm}^{-1}$, while the very weak band is located at $2108 \mathrm{~cm}^{-1}$. Upon application of pressure, the relative intensities are drastically altered: the intensity of the low-frequency band increases with respect to that of the high-frequency band, and the ratio is reversed at pressures close to $1400 \mathrm{MPa}$. The results shown in Figure 11a correspond to three different samples. The Raman spectra have been scaled relative to the intensity of the high-frequency band. The reversibility of the process was also monitored in the highpressure Raman spectroscopy measurements. Figure 11a shows that the Raman spectrum of $\mathbf{1}$ at ambient pressure obtained after treating the sample at $500 \mathrm{MPa}$ for $48 \mathrm{~h}$ closely resembles that

(58) Griffith, W. P.; Turner, G. T. J. Chem. Soc. A 1970, 858-862.

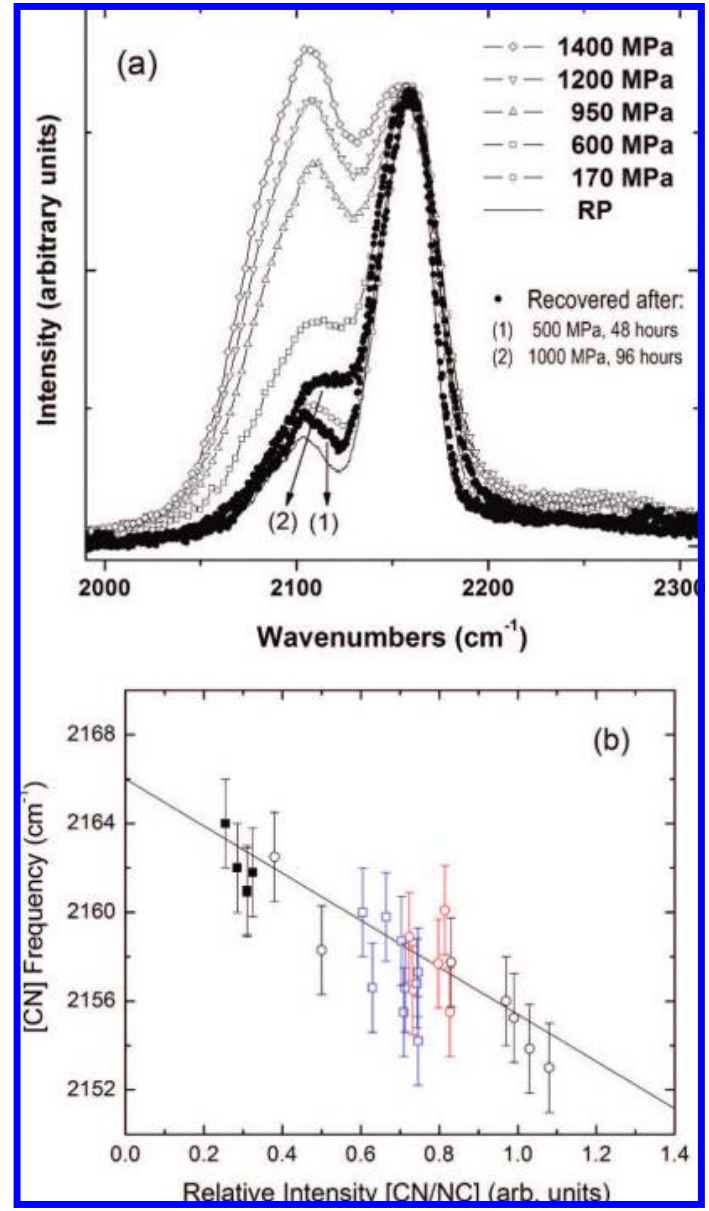

Figure 11. (a) Selected Raman spectra of $\mathbf{1}$ at different pressures and recovery conditions: $(\bigcirc)$ upstroke results; $(\bullet)$ recovered samples at room pressure (RP). (b) Linear correlation between the $\mathrm{CN}$ frequency and the relative intensities of the two bands assigned to $\mathrm{Cr}^{\mathrm{III}}-\mathrm{C} \equiv \mathrm{N}-\mathrm{Fe}^{\mathrm{II}}$ and $\mathrm{Cr}^{\mathrm{III}}-\mathrm{N} \equiv \mathrm{C}-\mathrm{Fe}^{\mathrm{II}}$ fragments. Different symbols stand for different samples.

described for a fresh sample. However, after treatment at a higher pressure (1000 MPa) for a longer time (96 h), irreversibility is observed to some extent. Experiments under uniaxial pressure conditions did not reveal significant differences in the observed changes in the relative intensities, as expected considering the moderate pressures reached in these experiments.

In addition, a red shift of the high-frequency band is observed as the pressure increases, and the pressure-induced shift correlates linearly with the relative intensity of the low-frequency band (Figure $11 \mathrm{~b}$ ), suggesting that $\mathrm{Cr}{ }^{\mathrm{III}}-\mathrm{N} \equiv \mathrm{C}-\mathrm{Fe}^{\mathrm{II}}$ fragments grow at the expense of the original $\mathrm{Cr}^{\mathrm{III}}-\mathrm{C} \equiv \mathrm{N}-\mathrm{Fe}^{\mathrm{II}}$ units. Furthermore, an isosbestic point near $2120 \mathrm{~cm}^{-1}$ is found when normalized intensities are used instead of relative intensities. This indicates a progressive pressure shift in the linkage isomerism, although the presence of electron transfer is still possible to some extent. The large frequency difference between the two observed bands $\left(56 \mathrm{~cm}^{-1}\right)$ seems to rule out an intrinsic spin crossover (process A). Although additional information could in principle be deduced from the analysis of metal-ligand vibrations in the $500-550 \mathrm{~cm}^{-1}$ spectral range, the presence of extra bands from the sapphire anvils in this region precluded an unambiguous analysis.

Pressure-Dependent Mössbauer Spectroscopy. The Mössbauer spectrum of $\mathbf{1}$ under room conditions (Figure 12) is identical to that described previously for iron(II) hexacyano- 


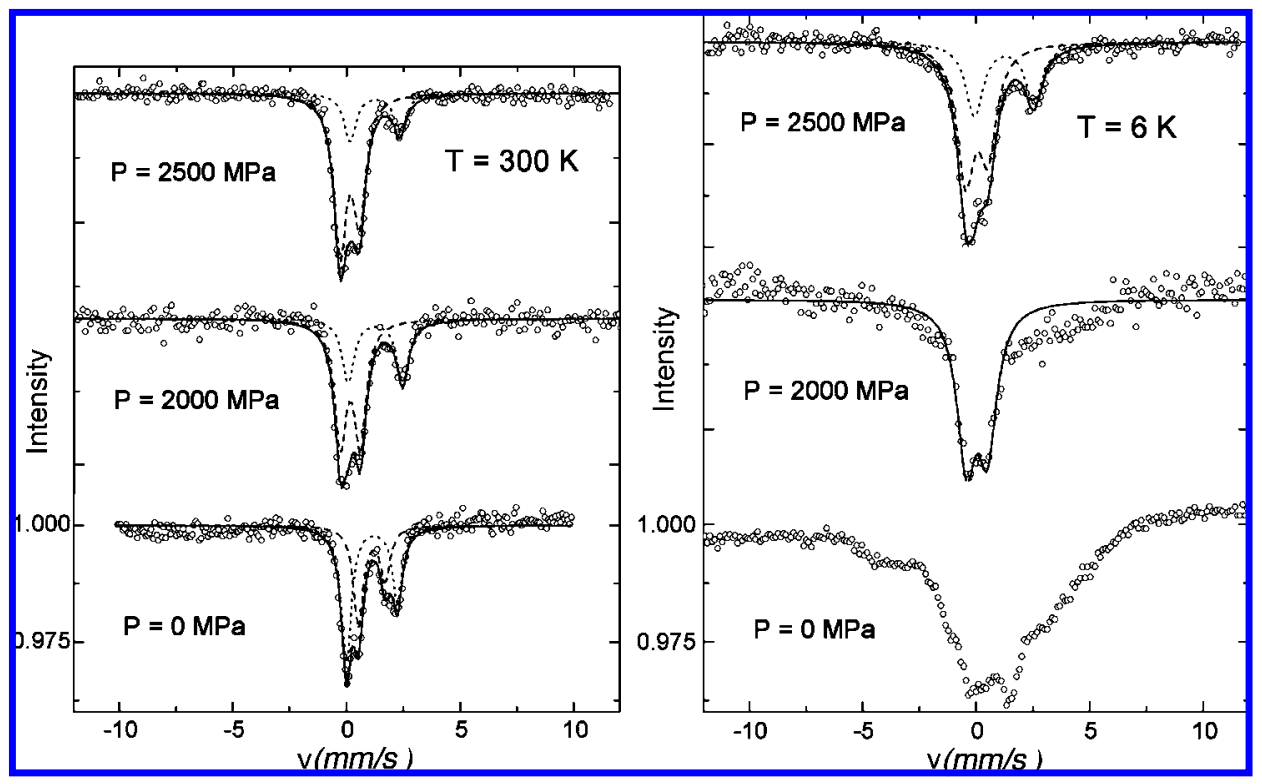

Figure 12. Pressure dependence of the Mössbauer spectrum of $\mathbf{1}$ at (left) 300 and (right) $6 \mathrm{~K}$.

Table 2. Mössbauer Parameters of 1

\begin{tabular}{|c|c|c|c|c|c|c|c|}
\hline \multirow[b]{3}{*}{$P(\mathrm{MPa})$} & \multirow[b]{3}{*}{$T(\mathrm{~K})$} & \multicolumn{4}{|c|}{ HS } & \multirow{2}{*}{\multicolumn{2}{|c|}{ LS }} \\
\hline & & \multicolumn{2}{|c|}{ site 1} & \multicolumn{2}{|c|}{ site 2} & & \\
\hline & & IS (mm/s) & $\mathrm{QS}(\mathrm{mm} / \mathrm{s})$ & IS $(\mathrm{mm} / \mathrm{s})$ & $\mathrm{QS}(\mathrm{mm} / \mathrm{s})$ & $\mathrm{IS}(\mathrm{mm} / \mathrm{s})$ & $\mathrm{QS}(\mathrm{mm} / \mathrm{s})$ \\
\hline 0 & 300 & $1.10(1)$ & $2.28(2)$ & $1.17(1)$ & $1.28(2)$ & - & - \\
\hline 2000 & & $1.10(1)$ & $2.75(3)$ & - & - & $0.28(2)$ & $0.60(2)$ \\
\hline 2500 & & $1.13(2)$ & $2.20(3)$ & - & - & $0.35(7)$ & $0.85(1)$ \\
\hline 0 & 6 & para & magnetic $r$ & elaxation & (PR) & $?$ & $?$ \\
\hline 2000 & & & $\mathrm{R}$ & - & - & $0.40(5)$ & $0.93(3)$ \\
\hline 2500 & & $1.23(2)$ & $2.62(3)$ & - & - & $0.03(1)$ & $0.98(2)$ \\
\hline
\end{tabular}

chromate(III). ${ }^{39}$ Two quadrupole doublets that correspond to high-spin $\mathrm{Fe}^{2+}$ cations in different coordination sites appear (Table 2). The doublet showing the smaller quadrupole splitting (QS) is assigned to iron(II) centers in an $\mathrm{FeN}_{6}$ coordination sphere. The second doublet corresponds to a less symmetric $\mathrm{FeN}_{4} \mathrm{O}_{2}$ environment. Under an applied pressure $(P=2000$ $\mathrm{MPa})$, the spectrum exhibits a new component characterized by a small QS and a less positive isomer shift (IS), indicating the presence of low-spin iron(II). The value of the QS for this low-spin $\mathrm{Fe}^{2+}$ ion indicates a strong departure from ideal cubic symmetry, as expected from the presence of $\left[\mathrm{Fe}(\mathrm{CN})_{x^{-}}\right.$ $\left.(\mathrm{NC})_{y}\left(\mathrm{H}_{2} \mathrm{O}\right)_{z}\right]$ species. At a higher pressure $(2500 \mathrm{MPa})$, the intensity of this band increases and its shape changes, corresponding to a different distribution of $\left[\mathrm{Fe}(\mathrm{CN})_{x}(\mathrm{NC})_{y}\left(\mathrm{H}_{2} \mathrm{O}\right)_{z}\right]$ sites. The Mössbauer spectrum obtained at $6 \mathrm{~K}$ (below the critical temperature) and ambient pressure (Figure 12) shows a complex structure, indicating the presence of magnetic order. At $P=2000 \mathrm{MPa}$, the high-spin components remain unresolved as a result of magnetic order, but the low-velocity signal due to the low-spin centers is well-resolved. Finally, at $P=2500$ $\mathrm{MPa}$, the splitting disappears, giving evidence for a pressureinduced transition to a paramagnetic phase. Thus, under these high-pressure conditions, $T_{\mathrm{C}}<6 \mathrm{~K}$. The data point to a pressuredriven $\mathrm{Fe}^{2+}$ spin crossover. However, the Raman results presented in the preceding section indicate that this spin change is subsequent to a linkage isomerization of the cyanide-metal bonds from the initial $\mathrm{Cr}^{\mathrm{III}}-\mathrm{C} \equiv \mathrm{N}-\mathrm{Fe}^{\mathrm{II}}$ isomer to the $\mathrm{Cr}^{\mathrm{III}}-\mathrm{N} \equiv \mathrm{C}-\mathrm{Fe}^{\mathrm{II}}$ isomer.

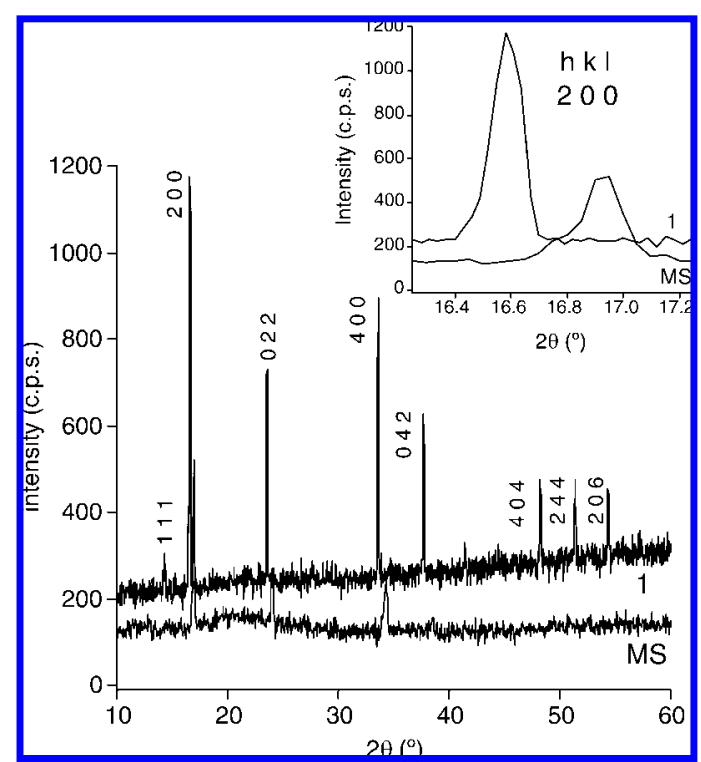

Figure 13. Comparison of the room-pressure X-ray powder diffractograms of a fresh sample of $\mathbf{1}$ and the metastable sample (MS) obtained after treatment at $P=1200 \mathrm{MPa}$ for $503 \mathrm{~h}$. The inset shows the changes observed in the (200) diffraction peak.

Powder X-ray Diffraction of a Metastable Sample. X-ray diffraction was performed at room pressure on a metastable sample (labeled as MS) obtained by treatment of $\mathbf{1}$ at $1200 \mathrm{MPa}$ until no further evolution in the magnetic properties was observed. After pressure release, the kinetics of relaxation of the material was very slow, and MS could be characterized by this technique. Figure 13 compares the X-ray diffractograms of $\mathbf{M S}$ and the original material 1. The diffractograms were indexed to a cubic unit cell. The intensity of the diffraction peaks of MS was weaker, pointing to a loss of crystallinity induced by mechanical stress during the pressure cycle. Only three reflections were observed, and their peak positions were shifted to higher $2 \theta$ values, indicating shorter interplanar distances $(d)$ in the crystal. The cubic unit cell parameter $a$ can be derived from the Miller indices $(h k l)$ via the expression $a=\left[\left(h^{2}+k^{2}\right.\right.$ $\left.\left.+l^{2}\right) d^{2}\right]^{1 / 2}$ using the value of $d$ obtained from Bragg's law. The 
mean value of $a$ calculated from the three reflections is 10.45(1) $\AA$, which is smaller than that obtained for the original sample (10.6720 $\AA$ ), providing additional confirmation of the linkage isomerism process. An estimate of the extent of isomerization can be obtained by considering that a contraction of the unit cell parameter $a$ from 10.65 to $10.05 \AA$ was observed in the thermally induced isomerization from $\mathrm{Fe}_{3}\left[\mathrm{Cr}(\mathrm{CN})_{6}\right]_{2}$ to $\mathrm{Cr}_{4}\left[\mathrm{Fe}(\mathrm{CN})_{6}\right]_{3}{ }^{37}$ This corresponds to $100 \%$ conversion. If it is assumed that $a$ decreases linearly with the increase in the number of $\mathrm{Cr}{ }^{\mathrm{III}}-\mathrm{N} \equiv \mathrm{C}-\mathrm{Fe}^{\mathrm{II}}$ moieties, the reduction of the cubic cell parameter $(\Delta a=10.6720 \AA-10.45 \AA=0.22 \AA)$ corresponds to $36 \%$ conversion in the isomerization reaction.

Soft X-ray Magnetic Circular Dichroism of a Metastable Sample. X-ray absorption spectroscopy (XAS) at the $\mathrm{L}_{2,3}$ edges of $3 \mathrm{~d}$ transition metals has been widely used in order to obtain information about the electronic structure of cyanide-bridged metal complexes, particularly their oxidation state, spin state, site symmetry, crystal-field splitting, and degree of covalency. 22,59,60 The technique is also very sensitive to charge-transfer effects and constitutes a direct probe of back-bonding in the $[\mathrm{Fe}$ $\left.(\mathrm{CN})_{6}\right]^{3-}$ and $\left[\mathrm{Fe}(\mathrm{CN})_{6}\right]^{4-}$ hexacyanoferrate anions. ${ }^{61}$ The use of circularly polarized X-ray beams gives access to X-ray magnetic circular dichroism (XMCD) spectra, which are powerful in the characterization of magnetic systems. ${ }^{62,63}$ They can give element-specific information about the magnetic moment and magnetic anisotropy. In bimetallic systems, it is thus possible to obtain the relative orientation of the magnetic moments of the different sublattices. This work has been performed for the $\mathrm{L}$ and $\mathrm{K}$ edges of several cyanide-based magnetic materials. ${ }^{64-66}$

Pressure-dependent XAS and XMCD studies at the K edge of $3 \mathrm{~d}$ transition elements are available in several synchrotron beamlines. ${ }^{67,68}$ However, the shorter penetration depth of soft $\mathrm{X}$-rays excludes the possibility of monitoring the absorption at the $\mathrm{L}_{2,3}$ edges inside a pressure cell. We thus used the same strategy as described in the preceding section. A metastable sample was obtained in the same way as for the X-ray diffraction study, and its XAS and XMCD spectra were recorded at ambient pressure. Comparison with the corresponding spectra of a fresh sample of $\mathbf{1}$ allowed us to characterize the structural changes that take place along the pressure-induced magnetic transformation.

The polarized absorption spectra $\left(\sigma^{\uparrow \uparrow}+\sigma^{\uparrow \downarrow}\right)$ at the Fe L edges of $\mathbf{1}$ and MS (Figure 14) reveal that the most intense peaks in

(59) Arrio, M.-A.; Sainctavit, P.; Cartier dit Moulin, C.; Mallah, T.; Verdaguer, M.; Pellegrin, E.; Chen, C. T. J. Am. Chem. Soc. 1996, $118,6422-6427$

(60) Arrio, M.-A.; Sainctavit, P.; Cartier dit Moulin, C.; Brouder, C.; de Groot, F. M. F.; Mallah, T.; Verdaguer, M. J. Phvs. Chem. 1996, 100, 4679-4684.

(61) Hocking, R. K.; Wasinger, E. C.; de Groot, F. M. F.; Hodgson, K. O.; Hedman, B.; Solomon, E. I. J. Am. Chem. Soc. 2006, 128, 1044210451.

(62) Funk, T.; Deb, A.; George, S. J.; Wang, H.; Cramer, S. P. Coord. Chem. Rev. 2005, 249, 3-30.

(63) Stöhr, J. J. Magn. Magn. Mater. 1999, 200, 470-497.

(64) Arrio, M.-A.; Scuiller, A.; Sainctavit, P.; Cartier dit Moulin, C.; Mallah, T.; Verdaguer, M. J. Am. Chem. Soc. 1999, 121, 6414-6420.

(65) Dujardin, E.; Ferlay, S.; Phan, X.; Desplanches, C.; Cartier dit Moulin, C.; Sainctavit, P.; Baudelet, F.; Dartyge, E.; Veillet, P.; Verdaguer, M. J. Am. Chem. Soc. 1998, 120, 11347-11352.

(66) Champion, G.; Escax, V.; Cartier dit Moulin, C.; Bleuzen, A.; Villain, F.; Baudelet, F.; Dartyge, E.; Verdaguer, M. J. Am. Chem. Soc. 2001, $123,12544-12546$.

(67) Piquer, C.; Grandjean, F.; Mathon, O.; Pascarelli, S.; Reger, D. L.; Little, C. A.; Long, G. J. Inorg. Chem. 2003, 42, 982-985.

(68) Pascarelli, S.; Mathon, O.; Aquilanti, G. J. Allovs Compd. 2004, 362, $33-40$.

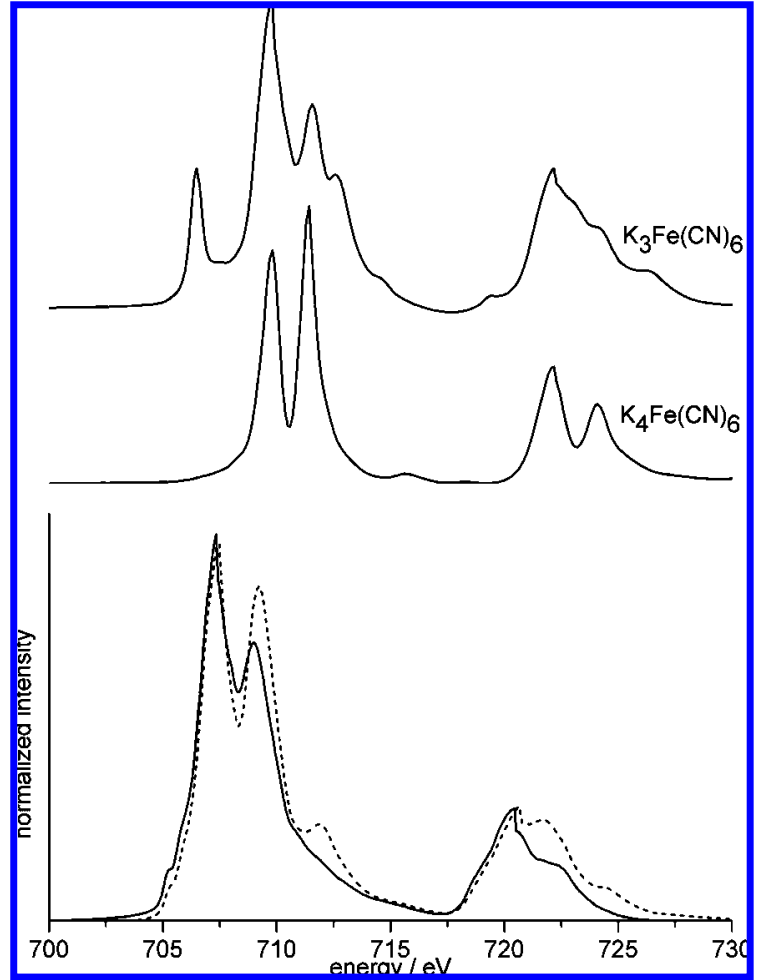

Figure 14. Polarized X-ray absorption spectra at the $\mathrm{Fe} \mathrm{L}_{2,3}$ edges of $\mathbf{1}$ (continuous line) and MS (dashed line). Polarized absorption spectra of the model compounds $\mathrm{K}_{3}\left[\mathrm{Fe}(\mathrm{CN})_{6}\right]$ and $\mathrm{K}_{4}\left[\mathrm{Fe}(\mathrm{CN})_{6}\right]$ are shown at the top for comparison.

the $\mathrm{L}_{3}$ and $\mathrm{L}_{2}$ absorption edges occur at energies of 707.4 and $720.6 \mathrm{eV}$, respectively. Other common absorption features are the well-resolved peak observed at $709.1 \mathrm{eV}$ and a shoulder at $\sim 722 \mathrm{eV}$. These two signals are more intense in the spectrum of MS, which also presents two additional satellite peaks located in the high-energy region of each edge (711.9 and $724.6 \mathrm{eV})$. The observation of high-energy satellites is a first indication of strong charge-transfer effects and points to the presence of $\mathrm{Fe}-\mathrm{CN}$ moieties. ${ }^{61}$ In order to examine the signal for the spectral changes due to $\mathrm{Fe}-\mathrm{CN}$ content in the MS sample, the spectra of potassium hexacyanoferrate(II) and potassium hexacyanoferrate(III) were recorded. The XAS $\left(\sigma^{\uparrow \uparrow}+\sigma^{\uparrow \downarrow}\right)$ spectrum of $\mathrm{K}_{3}\left[\mathrm{Fe}(\mathrm{CN})_{6}\right]$ exhibits a very strong peak in the pre-edge region (706.5 eV), where both $\mathbf{1}$ and $\mathbf{M S}$ are silent. This rules out the presence of $\mathrm{Fe}^{\mathrm{III}}-\mathrm{CN}$ units (and low-spin $\mathrm{Fe}^{\mathrm{III}}$ in general) in the material. On the other hand, the XAS $\left(\sigma^{\uparrow \uparrow}+\sigma^{\uparrow \downarrow}\right)$ spectrum of $\mathrm{K}_{4}\left[\mathrm{Fe}(\mathrm{CN})_{6}\right]$ reveals sharp absorptions at 709.8 and 711.4 $\mathrm{eV}$ as well as at 722.2 and $724.1 \mathrm{eV}$, fitting the positions of the additional high-energy satellites in the spectrum of MS. Thus, it seems that soft XAS confirms the presence of isomerized $\mathrm{Fe}^{\mathrm{II}}-\mathrm{CN}$ fragments in the metastable material.

We performed simulations of the different spectra using the ligand-field multiplet model ${ }^{69,70}$ in order to ascertain the nature of the different iron sites and quantify the extent of the isomerization reaction. Detailed information on the parameters used in the different calculations is gathered in Table 3 . The best fit of the polarized absorption spectrum of unisomerized compound $\mathbf{1}$ is based on the work on potassium-free $\mathrm{Fe}_{3}\left[\mathrm{Cr}(\mathrm{CN})_{6}\right]_{2}$ reported by Arrio and co-workers. ${ }^{59}$ The presence

(69) de Groot, F. Coord. Chem. Rev. 2005, 249, 31-63.

(70) de Groot, F.; Kotani, A. Core Level Spectroscopy of Solids; Taylor and Francis: New York, 2008. 
Table 3. Parameters Used for the Simulation of Polarized Absorption and Dichroism Spectra

\begin{tabular}{lccccc}
\hline & $\kappa$ & EG2/EF2 $(\mathrm{eV})$ & $\mathrm{e}_{\mathrm{g}} / \mathrm{t}_{2 \mathrm{~g}}$ ratio & $10 \mathrm{Dq}(\mathrm{eV})$ & charge transfer \\
\hline $\mathrm{Fe}^{\mathrm{II}}{ }_{\mathrm{HS}}$ & $90 \%$ & $3.5 / 2.0$ & $1.4 / 0.7$ & 1.1 & $9.9 \% \mathrm{~d}^{7} \underline{\mathrm{L}}$ \\
$\mathrm{Fe}^{\mathrm{III}}{ }_{\mathrm{HS}}$ & $80 \%$ & $3.5 / 2.0$ & $1.4 / 0.7$ & 1.2 & $9.7 \% \mathrm{~d}^{6} \underline{\mathrm{L}}$ \\
$\mathrm{Fe}^{\mathrm{II}}{ }_{\mathrm{LS}}$ & $60 \%$ & $1.0 / 0.85$ & $1.1 / 1.8$ & 3.7 & $52 \% \mathrm{~d}^{5} \mathrm{~L}$ \\
$\mathrm{Cr}^{\mathrm{III}}$ & $50 \%$ & $4.0 / 3.0$ & $1.0 / 1.4$ & 2.9 & $11.1 \% \mathrm{~d}^{2} \mathrm{~L}$
\end{tabular}

of $\mathrm{Fe}^{2+}$ sites in a weak crystal-field environment $(10 D q=1.0$ $\mathrm{eV}$ ) accounts for most of the intensity, indicating that the iron centers are in the high-spin state before pressure treatment. The small reduction factor of the Slater integrals $(\kappa=90 \%)$ used in the calculations is in agreement with the expected weak covalent character of the metal-ligand bond. Charge-transfer effects were introduced by addition of the ligand-to-metal charge transfer (LMCT) configuration $d^{6}+d^{7} \underline{L}$, where $\underline{L}$ means ligand hole. It was found that the ground state of the $\mathrm{Fe}^{2+}$ ions is a mixture of $90 \%\left|d^{6}\right\rangle$ and $10 \%\left|d^{7} \underline{L}\right\rangle$ configurations, confirming that the charge-transfer character of the metal-ligand bond is very weak, as expected for an $\mathrm{Fe}^{\mathrm{II}}-\mathrm{NC}$ coordination mode. The ratio of mixing parameters $\mathrm{e}_{\mathrm{g}} / \mathrm{t}_{2 \mathrm{~g}}$ was set to 2.0 (Kotani's rule). ${ }^{71}$ As mentioned earlier, it is necessary to include a high-spin $\mathrm{Fe}^{\mathrm{III}}$ spectral component to fit the intensity of the features observed at 709.1 and $722 \mathrm{eV}^{59}$ These $\mathrm{Fe}^{\mathrm{III}}-\mathrm{NC}$ sites originate from partial oxidation of the compound at the surface. The best simulated spectrum $\left(\sigma^{\uparrow \uparrow}+\sigma^{\uparrow \downarrow}\right)$ of the $\mathrm{Fe}_{2,3}$ edges for a fresh sample of $\mathbf{1}$ (Figure 15a) was obtained by using a linear combination of high-spin $\mathrm{Fe}^{\mathrm{II}}(80 \%)$ and high-spin $\mathrm{Fe}^{\mathrm{III}}(20 \%)$ spectral components. The high content of $\mathrm{Fe}^{\mathrm{III}}$ sites is not representative of the bulk, as soft X-rays have a very short penetration depth $(\sim 200 \AA)$ and probe mainly the surface of the material. In order to fit the spectrum of MS, we assumed that the amount of oxidized material at the surface remains constant throughout the pressure treatment. The presence of high-energy satellites was modeled by the introduction of a third spectral component, namely, a low-spin $\mathrm{Fe}^{\mathrm{II}}$ component exhibiting more covalent character in the metal-ligand bond $(\kappa=$ $60 \%)$, a larger crystal-field splitting parameter $(10 D q=3.7 \mathrm{eV})$, and a high degree of metal-to-ligand charge transfer (MLCT), resulting in a ground state that is a mixture of $48 \%\left|\mathrm{~d}^{6}\right\rangle$ and $52 \%\left|d^{5} \mathrm{~L}\right\rangle$ configurations. These LFM parameters (Table 3) compare well with those reported recently by Solomon and coworkers $^{61}$ and are equal to those obtained from fitting the absorption spectrum of $\mathrm{K}_{4}\left[\mathrm{Fe}(\mathrm{CN})_{6}\right]$ obtained under the same experimental conditions (see the Supporting Information). Clearly, a significant amount of isomerized $\mathrm{Fe}^{\mathrm{II}}-\mathrm{CN}$ moieties have been produced during the pressure cycle. Figure $15 \mathrm{~b}$ shows the experimental spectrum of MS and its best simulation. The best-fit data correspond to a linear combination of three spectral components: $62 \%$ high-spin $\mathrm{Fe}^{\mathrm{II}}-\mathrm{NC}, 18 \%$ low-spin $\mathrm{Fe}^{\mathrm{II}}-\mathrm{CN}$, and $20 \% \mathrm{Fe}^{\mathrm{III}}$. This means that in the bulk material, the content of low-spin $\mathrm{Fe}^{\mathrm{II}}-\mathrm{CN}$ centers is $22.5 \%$ out of the total $\mathrm{Fe}^{\mathrm{II}}$, which is consistent with the degree of isomerization in the metastable system as estimated from the magnetic studies (see below).

The X-ray polarized absorption spectrum $\left(\sigma^{\uparrow \uparrow}+\sigma^{\uparrow \downarrow}\right)$ of $\mathbf{1}$ at the $\mathrm{Cr} \mathrm{L}_{2,3}$ edges (Figure 16) is very similar to that previously reported for $\mathrm{CsNi}\left[\mathrm{Cr}(\mathrm{CN})_{6}\right] \cdot 2 \mathrm{H}_{2} \mathrm{O} .{ }^{59}$ The $\mathrm{L}_{3}$ edge shows a very sharp peak at $574.5 \mathrm{eV}$ together with a very intense and complex structure centered at $577.2 \mathrm{eV}$. The $\mathrm{L}_{2}$ edge exhibits a broad feature at $\sim 585.0 \mathrm{eV}$. Simulation of the spectral data was done by considering the effects of high covalence and charge transfer

(71) Kotani, A.; Okada, K. Tech. Rep. ISSP, Ser. A 1992, No. 2562.

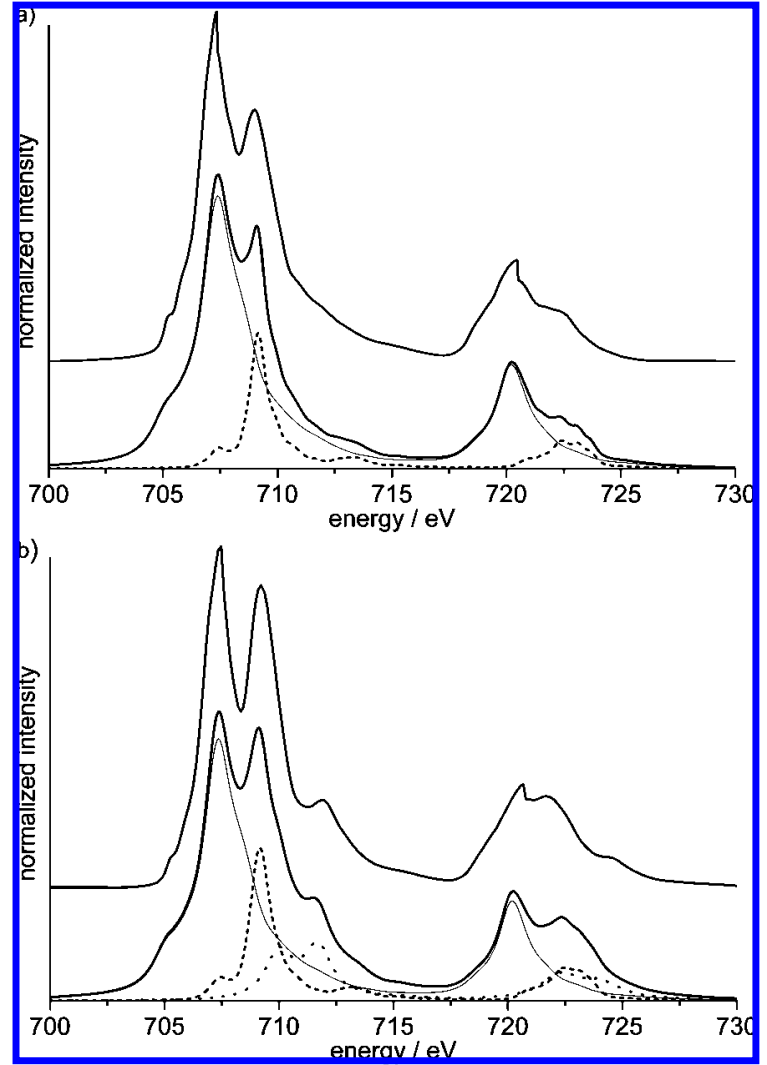

Figure 15. Experimental polarized X-ray absorption spectra $\left(\sigma^{\Uparrow \uparrow}+\sigma^{\Uparrow \downarrow}\right)$ at the Fe $\mathrm{L}_{2,3}$ edges of (a) $\mathbf{1}$ and (b) $\mathbf{M S}$ compared to their best-fit simulations. The contributions of the different iron centers are also included: high-spin $\mathrm{Fe}^{2+}$ (thin line), high-spin $\mathrm{Fe}^{3+}$ (dashed line), and low-spin $\mathrm{Fe}^{2+}$ (dotted line).

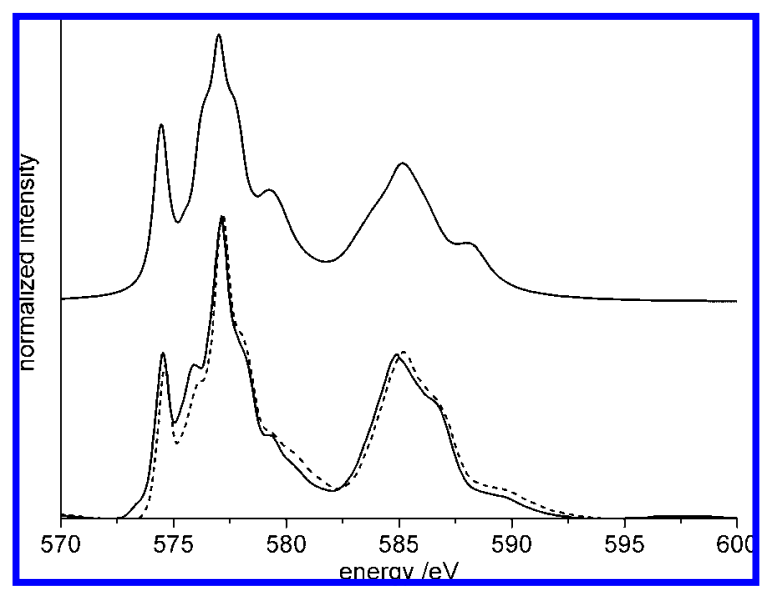

Figure 16. Experimental X-ray polarized absorption spectra at the $\mathrm{Cr}_{2,3}$ edges of $\mathbf{1}$ (continuous line) and MS (dashed line). The best-fit simulation of the spectrum of $\mathbf{1}$ is also shown above the experimental spectra.

in the electronic structure of the $\mathrm{Cr}^{3+}$ ions that lie in octahedral symmetry surrounded by six carbon atoms from cyanide ligands. This was done by reducing the Slater integrals by a factor $\kappa=$ $50 \%$ and adding the MLCT $\left|\mathrm{d}^{2} \mathrm{~L}\right\rangle$ configuration. The ground state of the chromium ion is indeed a mixture of $89 \%\left|\mathrm{~d}^{3}\right\rangle$ and $11 \%\left|\mathrm{~d}^{2} \mathrm{~L}\right\rangle$ configurations. As explained previously, the charge transfer from the chromium ions toward the cyanide ligands is due to the presence of $\pi$ back-bonding in the system. Since (in octahedral symmetry) $\pi$ bonding involves mainly the $t_{2 \mathrm{~g}}$ metal orbitals, the ratio of mixing parameters $\mathrm{e}_{\mathrm{g}} / \mathrm{t}_{2 \mathrm{~g}}$ was decreased to 


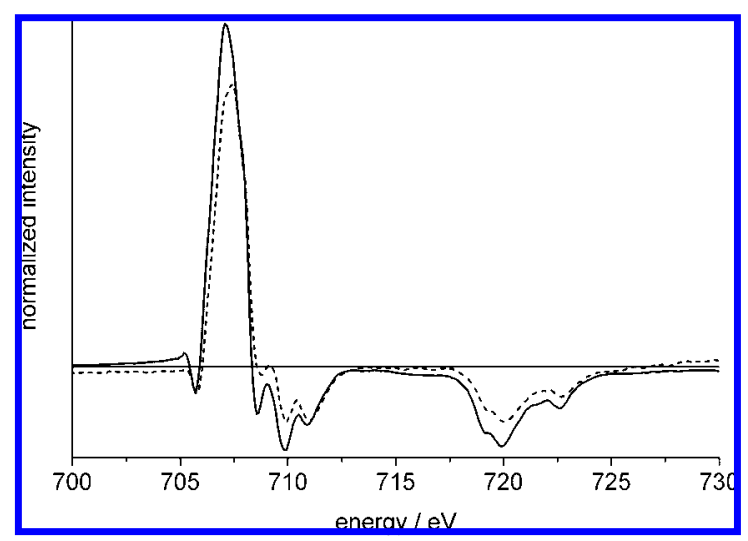

Figure 17. XMCD spectra at the $\mathrm{Fe}_{2,3}$ edges of $\mathbf{1}$ (continuous line) and MS (dashed line).

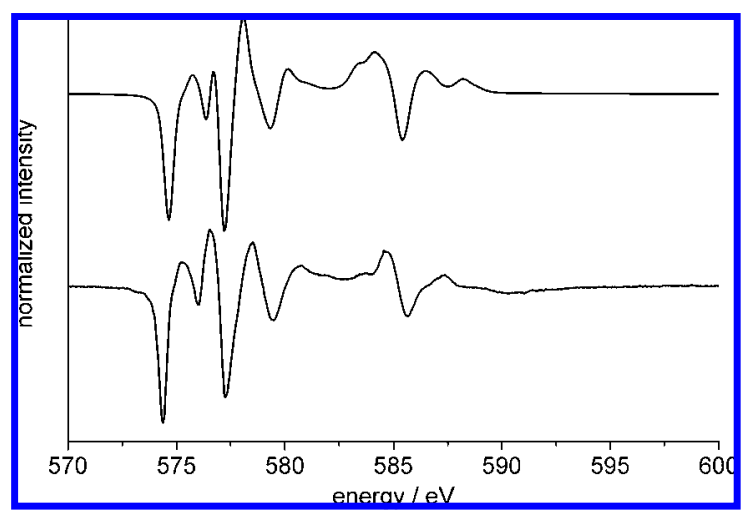

Figure 18. $\mathrm{XMCD}$ spectrum of $\mathbf{1}$ at the $\mathrm{Cr}_{2,3}$ edges (bottom) and its best-fit simulation (top).

0.7. The values of the parameters used in the spectral fitting are gathered in Table 3 . The value of the crystal-field splitting parameter $(10 D q=2.9 \mathrm{eV})$ is typical of a strong-crystal-field environment, although it is somewhat small in comparison with previously reported values for chromicyanide-based compounds. ${ }^{59,64}$ As expected, the X-ray absorption spectrum of MS is almost identical to that of $\mathbf{1}$. This indicates that the electronic configuration of the chromium(III) centers is unaffected by the pressure-induced transformation and is consistent with the linkage isomerization process.

XMCD $\left(\sigma^{\uparrow \uparrow}-\sigma^{\uparrow \downarrow}\right)$ measurements on both $\mathbf{1}$ and MS were recorded at $10 \mathrm{~K}$ in a magnetic field $H= \pm 5 \mathrm{~T}$. The dichroism signal of 1 (Figure 17) shows a positive peak in the Fe $\mathrm{L}_{3}$ edge at $707.5 \mathrm{eV}$ and a negative feature in the $\mathrm{Fe} \mathrm{L}_{2}$ edge centered at $719.9 \mathrm{eV}$. This means that the $\mathrm{Fe}$ magnetic moments lie parallel to the applied magnetic field. The presence of a significant amount of oxidized material complicates the spectral analysis, and it is not possible here to apply the sum rules ${ }^{72}$ in order to extract quantitative information about the magnetic moment of the iron sublattice. The XMCD spectrum at the $\mathrm{Cr}$ $\mathrm{L}_{2,3}$ edges (Figure 18) exhibits a more intricate structure, with two very intense negative peaks in the $\mathrm{L}_{3}$ edge at 574.4 and $577.3 \mathrm{eV}$ and a weak oscillating feature centered in the $\mathrm{L}_{2}$ edge region at $584.6 \mathrm{eV}$. Simulation of this dichroic signal was performed with the same set of parameters that were used to fit the absorption spectrum. Strikingly, a good agreement between the experimental and calculated data was only possible by setting

(72) Thole, T.; Carra, P.; Sette, F.; van der Laan, G. Phys. Rev. Lett. 1992, $68,1943-1946$. the magnetic field antiparallel to the $\mathrm{Cr}^{\mathrm{III}}$ magnetic moment. Element-specific magnetization curves (see the Supporting Information) confirm that the magnetic moments of the $\mathrm{Fe}^{\mathrm{II}}$ and $\mathrm{Cr}^{\mathrm{III}}$ units seem to be aligned in opposite directions, as in an antiferromagnetically coupled sample. This contrasts with the bulk magnetic properties of the system that point to ferromagnetic order. We attribute this strange behavior to a surface effect. The $S=5 / 2$ spins of the $\mathrm{Fe}^{3+}$ impurities $\left(\mathrm{d}^{5}\right.$ electronic configuration) present in the surface are likely to be coupled antiferromagnetically to the neighboring $\mathrm{Cr}^{3+}$ ions. This and other effects (e.g., vacancies, surface anisotropy) can modify the magnetic structure of the surface of the material with respect to the bulk. Also, it should be noted that the magnetic properties suggest a certain degree of canting. Again, the application of sum rules to extract valuable information on the spin and orbital magnetic moments is impossible here because of the strong overlap between the $\mathrm{L}_{3}$ and $\mathrm{L}_{2}$ edges.

Interestingly, the XMCD spectrum of MS (Figure 17) exhibits a shape identical to that of $\mathbf{1}$, but its intensity is lower by a factor of $82 \%$. This means that the new iron centers created by the pressure-induced rearrangement do not contribute to the dichroic signal (they are diamagnetic). This is again a confirmation of the presence of low-spin $\mathrm{Fe}^{\mathrm{II}}-\mathrm{CN}-\mathrm{Cr}^{\mathrm{III}}$ fragments in the metastable material.

\section{General Discussion}

The nature of the magnetic interactions between A and B metal sites in a Prussian blue analogue of formula $\mathrm{C}_{c} \mathrm{~A}_{a}\left[\mathrm{~B}(\mathrm{CN})_{6}\right]_{b} \cdot n \mathrm{H}_{2} \mathrm{O}$ has been clearly correlated to the electronic structure of the cyanide-bonded metal ions. ${ }^{6}$ It has been demonstrated that the exchange interaction between unpaired electrons occupying orbitals of the same symmetry set $\left[t_{2 g}(A)-t_{2 g}(B)\right.$ or $\left.e_{g}(A)-e_{g}(B)\right]$ is antiferromagnetic $(A F)$. On the contrary, when the unpaired electrons belong to orbitals of different symmetry $\left[\mathrm{t}_{2 \mathrm{~g}}(\mathrm{~A})-\mathrm{e}_{\mathrm{g}}(\mathrm{B})\right.$ or $\left.\mathrm{e}_{\mathrm{g}}(\mathrm{A})-\mathrm{t}_{2 \mathrm{~g}}(\mathrm{~B})\right]$, the interaction is ferromagnetic $(\mathrm{F})$. The sign and strength of the magnetic coupling between the adjacent metal ions is given by the sum of the different exchange interaction pathways. In the case of 1, the $\mathrm{Fe}^{2+}$ ion sits in a high-spin environment with a $\mathrm{t}_{2 \mathrm{~g}}{ }^{4} \mathrm{eg}_{\mathrm{g}}{ }^{2}$ electronic configuration and interacts with $\mathrm{a} \mathrm{Cr}^{3+}$ ion having a $\mathrm{t}_{2 \mathrm{~g}}{ }^{3}$ electronic configuration. The numbers of $\mathrm{F}$ and $\mathrm{AF}$ pathways are exactly the same (six). Because AF interactions are usually stronger in magnitude than $\mathrm{F}$ ones, a global weak AF coupling is expected for the $\mathrm{Cr}^{\mathrm{III}}-\mathrm{C} \equiv \mathrm{N}-\mathrm{Fe}^{\mathrm{II}}$ dimeric unit. Thus, as stated some years ago, the theory fails in predicting the short-range ferromagnetic interactions clearly evidenced in the magnetic behavior of $1 .^{73}$ In this context, our finding concerning the antiparallel orientation of $\mathrm{Cr}^{3+}$ and $\mathrm{Fe}^{2+}$ magnetic moments observed in the XMCD experiments on $\mathbf{1}$ is very interesting. It seems that surface effects (either intrinsic or due to partial oxidation of the iron sites) are important enough to favor an antiferromagnetic alignment of the spins. We are not aware of other observations of such surface effects in systems of this kind. Certainly, the compound lies in a range where a delicate balance between the F and AF contributions is established. An estimate of the absolute value of the exchange coupling parameter can be given by using the mean-field theory developed by Néel for three-dimensional cubic ferrimagnets. ${ }^{74}$ In this model, the critical temperature of $\mathbf{1}$ is given by

(73) Verdaguer, M.; Bleuzen, A.; Marvaud, V.; Vaissermann, J.; Seuleiman, M.; Desplanches, C.; Scuiller, A.; Train, C.; Garde, R.; Gelly, G.; Lomenech, C.; Rosenman, I.; Veillet, P.; Cartier, C.; Villain, F. Coord. Chem. Rev. 1999, 190, 1023-1047.

(74) Néel, L. Ann. Phys. Paris 1948, 3, 137-198. 


\section{Scheme 2}

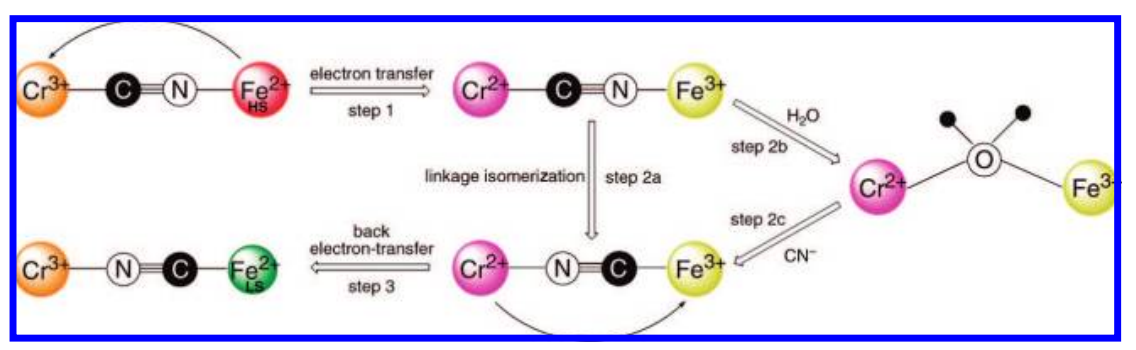

$$
T_{\mathrm{C}} \approx \frac{1}{2 k} y \sqrt{y}\left|J_{\mathrm{Cr}-\mathrm{Fe}}\right| \sqrt{n_{\mathrm{Cr}}\left(n_{\mathrm{Cr}}+2\right) n_{\mathrm{Fe}}\left(n_{\mathrm{Fe}}+2\right)}
$$

where $k$ is the Boltzmann constant, $y=z / 6$ is the $\mathrm{Cr} / \mathrm{Fe}$ stoichiometry $\left(z\right.$ is the number of $\mathrm{Cr}^{3+}$ nearest neighbors around the $\mathrm{Fe}^{2+}$ cation), $J_{\mathrm{Cr}-\mathrm{Fe}}$ is the value of the exchange coupling parameter, and $n_{\mathrm{Cr}}$ and $n_{\mathrm{Fe}}$ are the numbers of unpaired electrons of the metal ions. In our case, $T_{\mathrm{C}}=18.5 \mathrm{~K}, y=2.8 / 4, n_{\mathrm{Cr}}=$ 3 , and $n_{\mathrm{Fe}}=4$, so the value of the coupling parameter computed from eq 2 is $J_{\mathrm{Cr}-\mathrm{Fe}}=3.3 \mathrm{~K}=2.3 \mathrm{~cm}^{-1}$. This is slightly larger than the previously reported value of $1.9 \mathrm{~cm}^{-1}$ for $\mathrm{CsFe}\left[\mathrm{Cr}(\mathrm{CN})_{6}\right] \cdot 1.3 \mathrm{H}_{2} \mathrm{O},{ }^{41}$ as expected from the longer intermetallic distance observed in this compound (10.708 $\AA$ ) than in 1 (10.6720 ̊).

In the pressure-induced demagnetization process, the parameter of interest is now the number $Z$ of unaltered high-spin $\mathrm{Fe}^{2+}$ cations around the $\left[\mathrm{Cr}(\mathrm{CN})_{6}\right]^{3-}$ complex. This number decreases as isomerization proceeds and the low-spin state is favored. According to eq 2 , if it is assumed that $J_{\mathrm{Cr}-\mathrm{Fe}}$ is constant, the Curie temperature of $\mathbf{1}$ at a given pressure $\left(T_{\mathrm{C}}\right)_{P}$ can be expressed as follows:

$$
\left(T_{\mathrm{C}}\right)_{P}=T_{\mathrm{C}}\left(\frac{Z_{P}}{Z}\right)^{3 / 2}=T_{\mathrm{C}} \gamma_{P}^{3 / 2}
$$

where $\gamma_{P}$ is the fraction of high-spin $\mathrm{Fe}^{2+}$ cations at the pressure of interest. For example, at the highest pressure of the experiment, magnetization-versus-field measurements revealed an upper limit of $50 \%$ conversion of the isomerization reaction (i.e., $\left.\gamma_{P}=0.5\right)$. Substituting this value into eq 3 yields $\left(T_{\mathrm{C}}\right)_{P}=$ $6.5 \mathrm{~K}$, which is lower than the experimental value observed in the ac susceptibility measurements $(7.5 \mathrm{~K})$. On the other hand, for the metastable sample that orders at $T_{\mathrm{C}}=13 \mathrm{~K}$, eq 3 gives $\gamma_{P}=0.79$. This corresponds to a $21 \%$ content of low-spin iron(II) centers, which is close to that observed in the XAS experiment.

A second point of discussion concerns the unexpected reversible character of the pressure-induced phenomenon. Indeed, the well-known thermally induced isomerization from $\mathrm{Fe}_{3}\left[\mathrm{Cr}(\mathrm{CN})_{6}\right]_{2}$ to $\mathrm{Cr}_{4}\left[\mathrm{Fe}(\mathrm{CN})_{6}\right]_{3}$ is irreversible because of the very high thermodynamic stability of the ferrocyanide compound. ${ }^{37}$ It should be noted, however, that this reaction proceeds with a change of the $\mathrm{Fe} / \mathrm{Cr}$ ratio in the cyanide-based material from 1.5 to 0.75 , with the excess iron being released from the system as ferric oxyhydroxide upon heating. In our experiment at room temperature, the $\mathrm{Fe} / \mathrm{Cr}=3 / 2$ stoichiometry is retained throughout the process, and the ferrocyanide content in the final material should be very poor. For a random distribution of $\left[\mathrm{Cr}(\mathrm{CN})_{6}\right]^{3-}$ vacancies, the statistical probability of finding a $\mathrm{Fe}(\mathrm{NC})_{6}$ coordination mode in the lattice of $\mathbf{1}$ is less than $10 \%$. This is then the upper limit for the $\left[\mathrm{Fe}(\mathrm{CN})_{6}\right]^{4-}$ content in the system under pressure. The remaining $\mathrm{Fe}^{2+}$ cations are found in less symmetric and more unstable $\left[\mathrm{Fe}(\mathrm{CN})_{x}\left(\mathrm{H}_{2} \mathrm{O}\right)_{y}\right]^{(2-x)}$ environments that revert easily to the original $\left[\mathrm{Fe}(\mathrm{NC})_{x}\left(\mathrm{H}_{2} \mathrm{O}\right)_{y}\right]^{2+}$ form after pressure release. In this respect, it is interesting to compare this system with the related compound $\mathrm{CsFe}$ -
$\left[\mathrm{Cr}(\mathrm{CN})_{6}\right] \cdot 1.3 \mathrm{H}_{2} \mathrm{O} .{ }^{41}$ In this cesium-based system with $1 / 1$ stoichiometry, the $\mathrm{Fe} / \mathrm{Cr}$ ratio can be retained throughout the isomerization reaction (eq 4). Since no other iron byproducts need to be formed, the activation energy of the reaction is decreased, and the compound isomerizes readily (and irreversibly) at room temperature to a more stable phase.

$$
\mathrm{CsFe}\left[\mathrm{Cr}(\mathrm{CN})_{6}\right] \rightarrow \mathrm{CsCr}\left[\mathrm{Fe}(\mathrm{CN})_{6}\right]
$$

The driving force here is the stoichiometric formation of the ferrocyanide anion. In our case, the system adapts to the high pressure by increasing its density via the formation of some $\mathrm{Fe}^{\mathrm{II}}-\mathrm{CN}$ bonds. However, the energy gained by the system is not enough to stabilize this high-density structure under room conditions after pressure release. Only after severe pressure treatment can the compound be trapped in a metastable form that can be characterized by physical techniques. The origin of this irreversibility lies in the amorphization of the sample under extreme conditions, as indicated by XRD and also by Raman and UV-vis spectroscopies.

A third aspect deals with the role played by electron transfer in the pressure-induced structural rearrangement. As stated above, electron transfer is at the origin of the different switching phenomena previously reported for other Prussian blue analogues. Here, electron transfer is also very important, as it is involved in the mechanism of isomerization (Scheme 2). Preliminary pressure-dependent optical absorption measurements (see the Supporting Information) show that the intervalence charge-transfer absorption band of $\mathbf{1}$ shifts to lower energies when the pressure is increased, with $\mathrm{d} E / \mathrm{d} P=-0.133 \mathrm{meV} /$ $\mathrm{MPa}$. Thus, the first step of the isomerization mechanism probably involves a charge transfer from $\mathrm{Fe}^{2+}$ to $\mathrm{Cr}^{3+}$ to yield a $\mathrm{Cr}{ }^{\mathrm{II}}-\mathrm{C} \equiv \mathrm{N}-\mathrm{Fe}^{\mathrm{III}}$ unit. The formation of a labile $\mathrm{Cr}^{2+}$ cation enables a fast exchange of the coordination sites of the cyanide anions to give a $\mathrm{Cr}^{\mathrm{II}}-\mathrm{N} \equiv \mathrm{C}-\mathrm{Fe}^{\mathrm{III}}$ unit (step 2a). Back electron transfer (step 3) restores the initial oxidation states on each ion, affording $\mathrm{Cr}{ }^{\mathrm{III}}-\mathrm{N} \equiv \mathrm{C}-\mathrm{Fe}^{\mathrm{II}}$. This mechanism is similar to that previously described for the electrochemically induced isomerization of solid iron(II) hexacyanochromate(III) immobilized on the surface of a graphite electrode. ${ }^{75}$ The main difference is that the first and final steps of the electrochemical reaction involve one-electron reduction (oxidation) at the electrode instead of internal electron transfer. Also, the electrochemical reaction is irreversible. Scholz and co-workers ${ }^{75}$ proposed that flipping of the cyanide anions (steps $2 b$ and 2c) is likely the result of a fast exchange reaction between cyanide and water in the coordination sphere of $\mathrm{Cr}^{2+}$. Step $2 \mathrm{~b}$ was viewed as the origin of the irreversible behavior because the cyanide anions prefer the thermodynamically more stable $\mathrm{Cr}-\mathrm{N} \equiv \mathrm{C}-\mathrm{Fe}$ configuration. Thus, this ligand-exchange pathway is not consistent

(75) Dostal, A.; Schröder, U.; Scholz, F. Inorg. Chem. 1995, 34, 17111717. 
with the reversible character of the transformation. It is then possible that the flipping process takes place directly when induced by pressure. In any case, first-order kinetics should be observed for this process. From the data depicted in the inset of Figure 10, it is possible to obtain the time dependence of the decrease of the fraction $\gamma_{P}$ of high-spin $\mathrm{Fe}^{2+}$ at $P=1200 \mathrm{MPa}$ using eq 3. It can be shown (see the Supporting Information) that $\gamma_{P}$ follows a first-order law of the type $\gamma_{P}=A+B \mathrm{e}^{-t / \tau}$, with $A=0.640(14), B=0.186(12)$, and $\tau=200(40) \mathrm{h}$. The very slow kinetics of the transformation is consistent with the linkage isomerization process, as electron transfer or spin crossover phenomena take place with higher rates.

Finally, it is worth noting that the magnetic switching process could not be observed in powder samples of iron(II) hexacyanochromate(III) obtained by fast precipitation. ${ }^{76}$ It seems that the presence of isomerized $\mathrm{Cr}^{\mathrm{III}}-\mathrm{N} \equiv \mathrm{C}-\mathrm{Fe}^{\mathrm{II}}$ defects in single crystals is crucial in determining the magnetic properties of $\mathbf{1}$. These defects have a shorter intermetallic distance and create an internal (chemical) pressure in the system. They act as seeds of the more compact isomerized structure.

To conclude, it can be said that $\mathbf{1}$ joins a selected group of bimetallic cyanides in which magnetic ordering can be tuned by external stimuli. In most of the previously reported examples, the material undergoes electron transfer when the external perturbation is applied, with a subsequent change in the magnetic properties. In the present case, pressure triggers a more drastic but reversible structural transformation in the solid that is likely related to electron-transfer processes. It is certainly the interplay

(76) The powder sample was prepared as follows: A solution of $\mathrm{K}_{3}\left[\mathrm{Cr}(\mathrm{CN})_{6}\right](23 \mathrm{mg}, 0.072 \mathrm{mmol})$ in $10 \mathrm{~mL}$ of $50 \%$ aqueous ethanol was added to a solution of $\mathrm{Fe}\left(\mathrm{ClO}_{4}\right)_{2} \cdot n \mathrm{H}_{2} \mathrm{O}(27 \mathrm{mg}, 0.108 \mathrm{mmol})$ in the same solvent $(10 \mathrm{~mL})$. After a few minutes of stirring, the red precipitate was collected by centrifugation and dried. Yield: $75 \%$. IR $\left(\mathrm{KBr}, \mathrm{cm}^{-1}\right): 3422(\mathrm{O}-\mathrm{H}), 2160\left(\mathrm{Cr}^{\mathrm{III}} \mathrm{C} \equiv \mathrm{NFe}^{\mathrm{II}}\right), 1612(\mathrm{O}-\mathrm{H}), 486$ $\left(\mathrm{Cr}^{\mathrm{III}}-\mathrm{CN}\right)$. Anal. Calcd for $\mathrm{K}_{0.31} \mathrm{Fe}_{4}\left[\mathrm{Cr}(\mathrm{CN})_{6}\right]_{2.77} \cdot 18 \mathrm{H}_{2} \mathrm{O}: \mathrm{C}, 17.56$; H, 3.19; N, 20.48. Found: C, 17.53; H, 3.21; N, 20.14. Metal Anal.: $\mathrm{Cr}, 39.1$; $\mathrm{Fe}, 56.5$; K, 4.4. Found: $\mathrm{Cr}, 37.9 ; \mathrm{Fe}, 57.5 ; \mathrm{K}$, 4.6. The powder XRD data for this sample were very similar to those for $\mathbf{1}$ (see the Supporting Information). between magnetic coupling and electron transfer that makes this family of compounds very appealing. A localized electronic picture gives a simple explanation of the magnetic properties. However, electrons in these systems have a certain degree of freedom, allowing the observation of interesting electrochemical and conducting properties. In this work, we have shown that pressure-induced "rotation" of the cyanide anions is also possible in these defective structures. At the local level, the flipping movement can be considered as a molecular switch for the magnetic interaction between nearest neighbors. This concept paves the way for the design of bistable magnetic devices based on cyanide-bridged discrete molecules. It also predicts that other iron(II) cyanometalates with relatively long metal-carbon distances (>2.1 $\AA$ ) can exhibit piezomagnetism even with higher magnetic ordering temperatures. The old family of Prussian blue analogues still deserves much attention and will probably afford additional fascinating examples of structurally driven switching magnets such as $\mathbf{1}$.

Acknowledgment. We thank Prof. C. J. Gómez-García and J. M. Martínez-Agudo for the magnetic measurements. We acknowledge financial support from the European Union (NoE Magmanet), the Ministerio de Educación y Ciencia (Projects MAT2004-03849, MAT2007-61584, and CONSOLIDER-INGENIO in Molecular Nanoscience), and Generalitat Valenciana.

Supporting Information Available: Values of atomic parameters used in LFM calculations (Table S1), ac and dc susceptibility measurements on MS (Figures S1-S3), XAS spectrum of $\mathrm{K}_{4}\left[\mathrm{Fe}(\mathrm{CN})_{6}\right]$ and its best simulation (Figure $\mathrm{S} 4$ ), elementspecific magnetization curves (Figure S5), kinetics of the isomerization (Figure S6), pressure dependence of the chargetransfer band (Figure S7), powder X-ray diffraction (Figure S8) and TGA (Figure S9) results for $\mathbf{1}$, frequency dependence of the ac susceptibility of $\mathbf{1}$ under pressure (Figure S10), and CIF files for 1. This material is available free of charge via the Internet at http://pubs.acs.org.

JA8047046 